\title{
A IMPORTÂNCIA DA GRANITOGÊNESE TARDI-ARQUEANA (2.5 Ga) NA EVOLUÇÃO TECTONO-METAMÓRFICA DA PROVÍNCIA MINERAL DE CARAJÁS-O COMPLEXO GRANÍTICO ESTRELA E SUA AURÉOLA DE CONTATO
}

\author{
CARIOS EDUARDO DE MESOUITA BARROS *'** \& PIERRE BARBEY *
}

\begin{abstract}
THE ROLE OF THE LATE-ARCHEAN GRANITOGENESIS (2.5 Ga) IN THE TECTONO- METAMORPHIC EVOLUTION OF THE CARAJAS MINERAL PROVINCE-THE ESTRELA GRANITE COMPLEX AND ITS CONTACT AUREOLE An important magmatic event giving rise to moderately alkaline granitoids (Old Salobo Granite and Estrela Granite Complex) occurred in the Carajas Mining Province in Late-Archean times $(\sim 2.56 \mathrm{Ga})$. Moderately alkaline granite (A type) genesis is generally thought to be due to partial melting of either granulites or metaigneous rocks. These melts are considered to have very high temperatures and very low viscosity, promoting epizonal emplacement These Late-Archean granite bodies have imposed significant increase of thermal gradients, changes of the rheology of the metavolcanosedimentary country rocks (Salobo, Pojuca and Grão-Pará groups) and broadly overprinted the Rb-Sr isotopic systems in the Carajas region. Three domains have been discriminated in the Estrela Granite Complex host rocks: an external contact aureole $\left(\sim 450-550^{\circ} \mathrm{C}\right)$, an internal aureole $\left(-550-650^{\circ} \mathrm{C}\right)$, and the xenolith domains $\left(-650-850^{\circ} \mathrm{C}\right)$. The rocks of the external contact aureole are very slightly deformed, and affected by a discrete $\left(\mathrm{S}_{1 \mathrm{~m}}\right)$ foliation which is parallel to the primary regional lithological banding $\left(\mathrm{S}_{0}\right)$. In the internal aureole the host rocks show a very well developed sub vertical foliation $\left(\mathrm{S}_{2}\right)$ and/or lineation. In the metabasites of the internal aureole as well as from the xenoliths amphibole-bearing veins are very frequent.

Petrographic facies spatial distribution confirmed by geochemical, structural and aerogeophysical data show that the Estrela Granite Complex is built up by several plutons. The structural behavior of the complex is outlined by a magmatic layering $\left(\mathrm{S}_{0}\right)$, that is flat on the central domains and subvertical on the peripheral zones of each pluton. The spatial disposition of the magmatic layering $\left(\mathrm{S}_{0}\right)$ indicates that the Estrela Granite Complex emplacement was mainly controlled by ballooning. Subvertical magmatic layering and foliation $\left(\mathrm{S}_{1}\right)$ of E-W orientation have been developed as a response of both emplacement forces (ballooning) and regional coaxial horizontal shortening of N-S direction. Late mylonite zones $\left(\mathrm{S}_{1 \mathrm{~m}}\right)$ are due to the formation of mechanical instabilities at the end of the cooling history. Such structural evolution within progressive deformation and decreasing-thermal regimes is typical of syntectonic granites
\end{abstract}

Keywords: Archean, Carajas region, Estrela Granite Complex, contact metamorphism, tectonic aureole, granite emplacement.

RESUMO Na Província Mineral de Carajás, um importante evento magmático gerador de granitóides moderadamente alcalinos (Granito Old Salobo e Complexo Granítico Estrela) ocorreu no final do Arqueano ( 2,56 Ga). Granitos com tal assinatura geoquímica (tipo A) são muitas vezes originados pela fusão parcial de rochas metaígneas e/ou de granulitos. Os líquidos magmáticos produzidos são normalmente de temperaturas elevadas, e baixa viscosidade, sendo colocados em níveis crustais rasos. Na região de Carajás, estes corpos graníticos tardi-arqueanos impuseram aumentos significativos nos gradientes geotérmicos, afetaram os sistemas isotópicos Rb-Sr e criaram modificacões das condiç̃es reológicas de suas rochas encaixantes metavulcano-sedimentares (grupos Salobo, Pojuca, Grão-Pará) onde formaram auréolas metamórficas e tectônicas de comportamento dúctil.

Três domínios foram observados nas rochas metavulcano-sedimentares encaixantes do Complexo Granítico Estrela: uma auréola externa ( $\left.450-550^{\circ} \mathrm{C}\right)$, uma interna $\left(\sim 550-650^{\circ} \mathrm{C}\right)$ e os xenólitos $\left(\sim 650-850^{\circ} \mathrm{C}\right)$. Na auréola externa as rochas metavulcano-sedimentares se apresentam pouco estruturadas, mostrando uma foliação $\left(\mathrm{S}_{1}\right)$ discreta e concordante ao acamadamento regional $\left(\mathrm{S}_{0}\right)$. Na auréola interna as rochas encaixantes mostram uma forte foliação $\left(\mathrm{S}_{2}\right)$ subvertical e uma lineação de alto ângulo de caimento. Veios preenchidos por anfibólio são comuns nas metabásicas situadas na auréola interna e dos xenólitos.

A distribuição espacial das fácies petrográficas e os dados geoquímicos, estruturais e aerogeofísicos mostram que o Complexo Granítico Estrela

é formado por diferentes plútons. A organização estrutural do complexo é marcada por um bandamento magmático $\left(\mathrm{S}_{0}\right)$ de disposição concêntrica, ou seja, subvertical nas porções periféricas e concordante com os limites dos plútons, e subhorizontal nas partes centrais destes. A disposição espacial do bandamento magmático $\left(\mathrm{S}_{0}\right)$ indica que a colocação do Complexo Granítico Estrela foi controlada principalmente pelo mecanismo de ballooning. Uma foliação $\left(\mathrm{S}_{1}\right)$ e um bandamento magmático secundário associado, de direção geral E-W e mergulhos verticais, se desenvolve em resposta ao somatório de esforços ligados à colocação (ballooning) e de esforços regionais coaxiais de direção N-S. Zonas miloníticas ( $\mathrm{S}_{1 \mathrm{~m}}$ ) resultaram de instabilidade mecânicas no final da consolidação do complexo. Esta evolução estrutural, em regime de deformação progressiva e temperatura decrescente, comprova o comportamento sintectônico do Complexo Granítico Estrela.

Palavras-chave: Arqueano, região de Carajás, Complexo Granítico Estrela, metamorfismo de contato, auréola tectônica, colocação de granitóides.

INTRODUÇÃo A Província Mineral de Carajás (Fig. 1), situada na parte sudeste do Cráton Amazônico (Almeida et al. 1981) mais exatamente na parte oriental da Província Tapajós (Amaral 1984), tem merecido um grande destaque no meio geológico devido ao seu enorme potencial econômico e riqueza mineral.

Diferentes modelos de evolução tectono-metamórfica têm sido propostos para a Província Carajás, o que denota a falta de consenso e a necessidade de estudos adicionais visando modelos alternativos. No entanto, é importante ressaltar que numerosos trabalhos realizados, até o presente, por empresas privadas e estatais e no meio acadêmico, têm produzido uma vasta quantidade de dados, incrementando a qualidade das cartas geológicas e possibilitando a individualização e/ou a correlação de unidades litoestratigráficas distintas.

No início da década de noventa, alguns trabalhos apontavam a existência de granitóides tardi-arqueanos de assinatura alcalina próximos do alvo de Salobo e a leste da Serra dos Carajás. Entretanto, naquele momento, o papel destes granitóides no quadro evolutivo da região era ainda timidamente compreendido. A melhor caracterização da evolução estrutural destes corpos e das suas relações com as rochas encaixantes, aliado a um número significativo de dados geocronológicos tem sido fundamentais para alcançar um nível de conhecimento satisfatório da geologia arqueana da região de Carajás. O presente trabalho sintetiza os dados obtidos durante a tese de doutorado do primeiro autor e demonstra a importância do magmatismo granítico alcalino na evolução tectono-termal da Província. As conclusões alcançadas são o fruto da integração da cartografia geológica, petrologia ígnea e metamórfica, da geologia estrutural/microestrutural e da geocronologia.

Os dados de química mineral apresentados neste trabalho foram obtidos em microssonda eletrônica $(10 \mathrm{~A} ; 15 \mathrm{kV} ; 1 \mathrm{Os})$ no Service de Microanalyse da Universidade de Nancy I (França) e as análises químicas completas de rochas foram realizadas nos laboratórios do Centre de Recherches Pétrographiques et Géochimiques (CRPGCNRS, Vandoeuvre-Franca) pelos métodos ICP-AES para os elementos maiores, menores e Sc, e ICP-MS para os elementos traço. As análises parciais de rochas foram realizadas nos laboratórios do Centro de Geociências da Universidade Federal do Pará, onde se utilizou o método de fluorescência de raios-X para os elementos traço e maiores, exceto $\mathrm{MgO}$ e $\mathrm{Na}_{2} \mathrm{O}$, que foram analisados por absorção atômica; $\mathrm{Fe}_{2} \mathrm{O}_{3}$ foi determinado por via úmida. A nomenclatura dos clinopiroxênios e dos anfibólios segue as classificacões de Morimoto (1988) e de Leake et al. (1997), respectivamente. A classificação de Streckeisen (1976) foi empregada para denominar as diferentes fácies petrográficas do Complexo Granítico Estrela.

GEOLOGIA REGIONAL A Província Mineral de Carajás (Fig. 2), situada na parte sudeste do Cráton Amazônico (Almeida et al. 1981) é formada por diferentes unidades litoestratigráficas, a maioria de idade arqueana:

Complexo granulítico (Complexo Pium) A sul da Serra dos Carajás afloram corpos alongados (Fig. 2) na direcão E-W de granulitos básicos do Complexo Pium (Hirata et al 1982, Araújo et al. 1988).

* Université Henri Poincaré-Nancy I e Centre de Recherches Pétrographiques et Géochimiques (CRPG-CNRS).

** Deptfi. de Geoquímica e Petrologia (Universidade Federal do Pará). Grupo Petrologia de Granitóides. Bolsista do Conselho Nacional de Desenvolvimento Científico e Tecnológico (CNPq). 
Rodrigues et al (1992) obtiveram uma idade ( $\mathrm{Pb}-\mathrm{Pb}$ rocha total) de $3050 \pm 57 \mathrm{Ma}$, interpretada como a idade de cristalização dos protólitos. Datações $\left({ }^{40} \mathrm{Ar} /{ }^{39} \mathrm{Ar}\right)$ forneceram idades de $1963 \pm 17 \mathrm{Ma}$ a 1986 $\pm 37 \mathrm{Ma}$ em biotita e de 2,5 e 2,7 Ga em anfibólio (Renne et al 1988).

Seqüência metavulcano-sedimentar de Rio Maria As sequiências do tipo greenstone de Rio Maria foram inicialmente descritas por Cordeiro (1982) e Hirata et al. (1982) como sendo constituídas de uma unidade basal (Grupo Babaçu) e de uma superior (Grupo Lagoa Seca). A unidade basal engloba espessos derrames de basaltos, intercalações de talco xistos, metatufos, metacherts e de formações ferríferas. A unidade superior é formada por metapelitos, metapsamitos e meta-riodacitos. Datações (U-Pb em zircões) fornecem idades de $2904 \pm 22$ Ma (Macambira \& Lancelot 1992) e de $2979 \pm 5$ Ma para as rochas vulcânicas félsicas do Grupo Lagoa Seca (Pimentel \& Machado 1994).

Granitóides da região de Rio Maria O Tonalito Arco Verde aflora a sul de Rio Maria, e apresenta um quimismo cálcio-alcalino pobre em $\mathrm{K}_{2} \mathrm{O}$ e uma estruturação que indica colocação sintectônica a esforços coaxiais de direção N-S (Althoff et al. 1995, Althoff 1996). Datações (U-Pb em zircões) apontaram uma idade de $2957 \pm 25 \mathrm{Ma}$ para estas rochas (Macambira 1992). O Granito Guarantã, situado a sul do município de Rio Maria, é constituído de monzogranitos cálcioalcalinos fortemente deformados (Althoff et al. 1995, Althoff 1996).

A norte do município de Rio Maria afloram o Tonalito Parazônia e o Trondhjemito Mogno (DOCEGEO 1988). Datações U-Pb em titanita forneceram idades de 2871 Ma para o primeiro e de 2858 Ma para o segundo (Pimentel \& Machado 1994). De ampla distribuição superficial, o Granodiorito Rio Maria (Medeiros \& DalTAgnol 1988) apresenta foliação magmática moderada, epidotização generalizada e assinatura cálcio-alcalina. Datações U-Pb em zircão indicaram uma idade de 2,87 Ga para estas rochas (Medeiros \& Dall'Agnol 1988, Macambira \& Lancelot 1991, Pimentel \& Machado 1994, Leite \& Dall'Agnol 1994).

O Granito Xinguara é constituído de monzogranitos e sienogranitos cálcio-alcalinos (Leite, 1995, Leite \& Dall'Agnol op. cit.), cuja idade mínima (U-Pb em zircões) é de $2800 \pm 18 \mathrm{Ma}$ (Macambira op. cit.). A sul de Rio Maria aflora o Granito Mata Surrão (Duarte \& Dall'Agnol 1992), igualmente cálcio-alcalino, datado em $2875 \pm 20 \mathrm{Ma}(\mathrm{Pb}-\mathrm{Pb}-$ rocha total; Lafon et al. 1994).

Granitóides gnáissicos (Complexo Xingu) Granitóides fortemente deformados afloram nas proximidades do alvo Salobo, sob

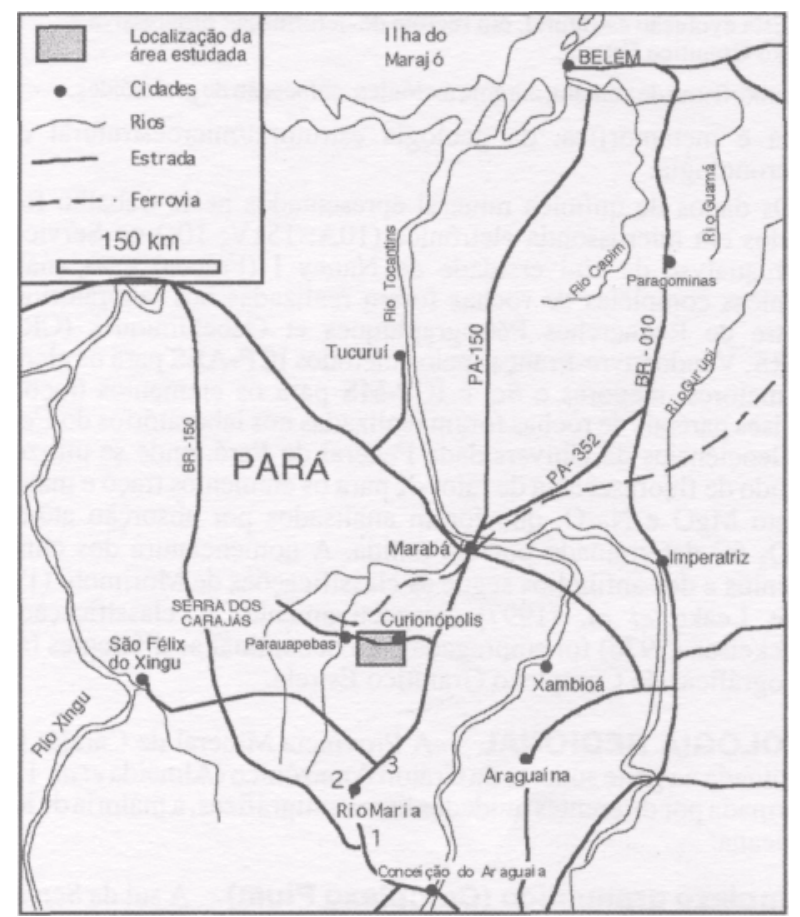

1 - Tonalito Arco Verde, granitos Guarantã e Mata Surrão.

2 - Granodorito Rio Maria, Trondhjemito Mogno, Tonalito Parazônia.

3 - Granito Xinguara.

Figura 1-Mapa de localização da área estudada. a denominação de Gnaisse Cascata, e na pedreira CIMCOP (Lindenmayer 1990, M achado et al. 1991). Datações U-Pb em zircões mostram idades de $2851 \pm 4$ Ma para as rochas da pedreira CIMCOP e de 2841 Ma para o Gnaisse Cascata (Machado et al. 1991). Idades (U-Pb em titanitas) de $2555 \mathrm{Ma}$, obtidas nestes granitóides, foram interpretadas como o resultado de um evento de reativação do embasamento (Machado et al. op. cit.). Naquela ocasião, as causas desta reativação não puderam ser identificadas.

Seqüência metavulcano-sedimentar de Carajás $\mathrm{Na}$ região de Carajás afloram abundantes rochas metavulcano-sedimentares dos grupos Salobo, Pojuca, Grão-Pará e Rio Novo (Fig. 2), todos pertencentes ao Supergrupo Itacaiúnas (DOCEGEO 1988). O Grupo Grão-Pará é formado por duas unidades de rochas vulcânicas básicas, intercaladas por níveis de formações ferríferas da Formação Carajás (Beisiegel et al 1973, Meireles et al 1984). Hirata et al (1982) consideram que as rochas máficas do Grupo Grão-Pará, fazem parte de um vulcanismo tolético, afetado por hidrotermalismo em condições submarinhas. Segundo aqueles autores, as rochas máficas do Grupo Grão-Pará seriam mais jovens que as da Seqüência Salobo-Pojuca.

Segundo Hutchinson (1979) e Lindenmayer \& Fyfe (1992) as rochas dos grupos Grão-Pará, Salobo e Pojuca são contemporâneas, formadas em ambiente continental, mas metamorfisadas de modo diferente. As rochas do Grupo Salobo teriam sido metamorfisadas em condições mais severas (fácies anfibolito hornfels) (Lindenmayer et ai 1994b). Gibbs et al (1986) interpretaram os basaltos e riolitos da Serra dos Carajás como o resultado de um vulcanismo bimodal continental, cuja origem estaria ligada à assimilação de material crustal pelo material basáltico originado no manto (Oliveira et al 1993). De acordo com Teixeira \& Eggler (1994) e Rivallenti et al (1992) o vulcanismo Grão-Pará representa uma série cálcio-alcalina gerada em zona de subducção.

Datações (U-Pb em zircões) realizadas em riolitos do Grupo GrãoPará (Wirth et al 1986) e em rochas metabásicas dos grupos Salobo e Pojuca (Machado et al 1991) indicaram uma idade de $2758 \pm 39 \mathrm{Ma}$

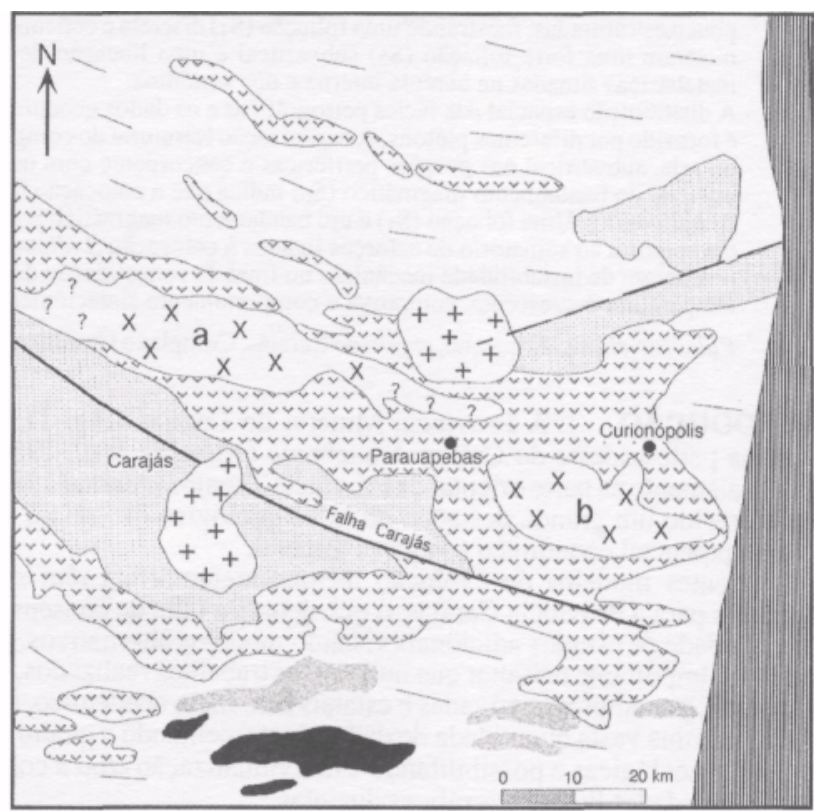

Faixa Araguaia

Granitos proterozóicos

Granitóides tardi-arqueanos a - Granito Old Salobo

b - Complexo Granítico Estrela

Formação Águas Claras Supergrupo Itacaiúnas

Granito Plaquê

Complexo Xingu

Complexo Pium

Figura 2-Mapa geologico esquemático da regido de Carajds (modificado de Docegeo 1988, Araújo et al. 1988, Barros et al 1997). 
para os primeiros e de $2761 \pm 3$ Ma e $2732 \pm 2$ Ma para as últimas Idades (U-Pb em zircões) semelhantes $(2763 \pm 6 \mathrm{Ma})$ foram obtidas por Machado et al. (1991) em rochas máfícas do Complexo Luanga, situadas próximo da Serra Pelada. Datações de titanita pelo método $\mathrm{U}-\mathrm{Pb}$ acusaram, igualmente, idades de $2555 \mathrm{Ma}$ em rochas metabásicas do alvo Salobo (Machado et al. op . cit.).

Granitóides peraluminosos Os muscovita-biotita leucogranitos da Suíte Plaque ocorrem como corpos alongados (Fig. 2) na direção E-W (Araújo et al. 1988). Estas rochas têm assinatura metaluminosa à peraluminosa, forte fracionamento dos elementos terras raras e anomalias negativas de európio (Jorge-João et al. 1991, Macambira et ai. 1996). Datações (Pb-Pb-rocha total) forneceram idades de $2727 \pm$ 29 Ma para estes granitos (Avelar 1996).

A cobertura de plataforma (Formação Águas Claras) A cobertura de plataforma (Fig. 2), representada pela Formação Águas Claras (Araújo et al 1988), engloba sedimentos de ambientes litorâneos a fluviais, controlados por tempestades (Nogueira 1995 , Nogueira et al. 1995).

Diques e sills máficos $\mathrm{Na}$ Serra dos Carajás ocorrem numerosos diques e sills de diabásios e gabros cortando rochas sedimentares anquimetamórficas da Formação Aguas Claras (Soares et al. 1994). Estas rochas máficas são comparáveis aos toleítos e aos basaltos subalcalinos e continentais (Barros et al. 1994). Estes diabásios e gabros foram afetados por duas fases de alteração hidrotermal: a primeira de transformações estáticas $\left(700^{\circ} \mathrm{C}\right)$, e a segunda associada a falhamentos $\left(450^{\circ} \mathrm{C}\right)$. Datações (U-Pb em zircões) forneceram idades de $2556 \pm 219 \mathrm{Ma}$ a $2708 \pm 37 \mathrm{Ma}$ (Mougeot et al. 1996) e $2645 \pm 12$ Ma (Dias et al. 1996) para estes metagabros.

Granitóides alcalinos tardi-arqueanos Os granitóides alcalinos tardi-arqueanos da região de Carajás são representados pelo Granito Old Salobo (Lindenmayer 1990) e pelo Complexo Granítico Estrela (Barros 1991,1997).

O Granito Old Salobo ( $2573 \pm 3 \mathrm{Ma}$, U-Pb zircão), situado a norte da Serra dos Carajás, é foliado e tem quimismo alcalino moderado, levemente sódico e metaluminoso (Lindenmayer 1990, Machado et al. 1991, Lindenmayer et al. 1994a). Uma idade similar de $2525 \pm 38 \mathrm{Ma}$ foi obtida por Souza (1996) pelo método Pb-Pb (rocha total) em granitos situados a alguns quilômetros do ponto amostrado por Machado et al. (1991).

O Complexo Granítico Estrela, situado entre os municípios de Curionópolis e Parauapebas (Figuras l e 2), foi considerado como um conjunto de gnaisses (Gnaisse Estrela) do embasamento (Complexo Xingu) (Araújo et al. 1988, Costa et al. 1990). Estudos mais detalhados (Barros 1991, Barros \& Dall'Agnol 1994) mostram que esta unidade é formada por granitóides deformados em regime dúctil. Recentemente, Barros (1997) passou a denominar esta unidade de Complexo Granítico Estrela. A idade mínima (Rb-Sr-rocha total) de $2527 \pm 34$ Ma $(\mathrm{RI}=0,7018 \pm 0.00197)$ do Complexo Granítico Estrela (Barros et al. 1992) é muito semelhante a do Granito Old Salobo.

Granitóides proterozóicos Os granitóides proterozóicos afloram em toda a região como batólitos discordantes (Fig. 2) formados por rochas isotrópicas de quimismo moderadamente alcalino (Silva et al. 1974, Hirata et al. 1982.DOCEGEO 1988,Dall'Agnol et al. 1994, Gonçalez et al. 1988, Rios 1991). Datacões (U-Pb em zircão e Pb-Pb rocha total) apontam idades de 1,88 Ga para estes granitos (Wirth et al 1986, Machado et al op. cit., Barbosa et al 1995).

Diques e corpos máficos proterozóicos $\mathrm{Na}$ região de Carajás, o magmatismo máfico do Proterozóico se manifesta como diques de diabásio e pequenos corpos de gabro (Silva et al 1974). Gomes et al (1975) obtiveram uma idade (K-Ar em anfibólio) de 550 $\pm 30 \mathrm{Ma}$ em diabásios da Serra do Buritirama.

Sedimentos fanerozóicos Nos domínios da Serra do Paredão afloram conglomerados, arenitos avermelhados, arcóseos e argilitos do Grupo Paredão (Araújo \& Costa 1994), recentemente correlacionados às rochas siluro-devonianas do Grupo Serra Grande da Bacia do Parnaíba (Pinheiro 1997).

OS MODELOS PREEXISTENTES DE EVOLUCCÃO TECTONO-METAMÓ RFICA DE CARAJÁS Dentre os modelos de evolução tectônica e metamórfica da região de Carajás se contrapõem os que admitem uma evolução polifásica aos que consideram uma evolução segundo um único evento metamórfico de idade arqueana. Um quadro também não conclusivo existe a respeito da evolução cinemática arqueana de Carajás:
-Hirata et al. (1 982) e Meireles et al (1984) propõem uma evolucão policíclica. Cada fase de geração de rochas supracrustais teria sido sucedida por uma fase de deformação. A primeira seqüência seria representada pelo greenstone do Grupo Rio Novo, cujas rochas teriam sido afetadas por intenso dobramento resultante em geometria anticlinal associado a metamorfismo de fácies xisto verde. Uma nova fase teria originado as rochas do Grupo Salobo-Pojuca, submetidas posteriormente à intensa deformação e a metamorfismo de fácies anfíbolito. Uma fase posterior teria originado as rochas do Grupo Grão-Pará, metamorfisadas em fácies xisto verde.

- a evolução arqueana da região de Carajás estaria ligada a grandes zonas de cisalhamento direcional sinistrai e oblíqua, e que teria imposto uma trama milonítica regional (Araújo et al 1988, Araújo et al 1994, Costa et al 1990).

- as seqüências Salobo, Pojuca e Grão-Pará seriam contemporâneas. As duas primeiras seriam variações laterais de grau metamórfico mais elevado, de fácies piroxênio hornfels $\left(750^{\circ} \mathrm{C}-2,5 \mathrm{~kb}\right)$ (Hutchinson 1979, Lindenmayer 1990). Esta fase metamórfica teria ocorrido há 2732-2742 Ma e estaria ligada a processos de magma underplating em um contexto de rift continental (Lindenmayer \& Fyfe 1991, Lindenmayer et al. 1994b). Posteriormente, Winter (1994) considerou que este metamorfismo teria ligação com o Granito Old Salobo, considerado, então, como um corpo granítico sintectônico.

- a evolução tectônica de Carajás seria marcada por transpressão sinistrai dúctil $(>2,8 \mathrm{Ga})$, transpressão sinistrai rúptil-dúctil $(2,8-2,7$ $\mathrm{Ga})$, transtensão dextral rúptil (2,5-2,6 Ga), transpressão sinistrai rúptil (Falha Carajás) (>1,9 Ga) e finalmente transtensão (1,8-1,0 Ga) (Pinheiro 1997, Pinheiro \& Holdsworth 1997).

COMPLEXO GRANÍTICO ESTRELA Estrutura O Com plexo Granítico Estrela possui uma forma grosseiramente elíptica, com eixo maior de direção EW (Fig. 3). Entre as estruturas planares destacam-se um bandamento magmático primário $\mathrm{S}_{0}$, uma foliação $\mathrm{S}_{1}$ à qual podem estar associados um bandamento magmático secundário e uma foliação milonítica $\mathrm{S}_{\mathrm{m} \text {. }}$

$\mathrm{O}$ bandamento magmático primário $\mathrm{S}_{0}$ é desenhado pela alternância de finos níveis ricos em minerais máficos e de finos níveis quartzofeldspáticos. A presença de finos veios leucocráticos, concordantes a este bandamento, salienta muitas vezes esta estrutura planar. O bandamento magmático $\mathrm{S}_{0}$ apresenta uma trajetória concêntrica e concordante aos limites do complexo, ou seja, mergulho subvertical na periferia (Figs. 3 e 4) e subhorizontal nas partes centrais do maciço (Fig. 3). A disposicão deste bandamento permite definir uma arquitetura dômica (cf. Balk 1937) para o Complexo Granítico Estrela (Fig. 3).

$\mathrm{O}$ bandamento magmático $\mathrm{S}_{0}$ é afetado por uma foliação $\mathrm{S}_{1}$ penetrativa na escala do corpo, e definida pela orientação preferencial de minerais máficos e agregados achatados de quartzo. A esta foliação pode estar associado um bandamento magmático secundário subparalelo à foliação $S_{b}$ e desenhado pela alternância de níveis leucocrático decimétricos a centimétricos e de níveis ricos em minerais máficos. Na parte sul do maciço estas estruturas planares apresentam direção geral E-W e mergulhos que variam de $70^{\circ} \mathrm{S}$ a subvertical, sendo neste setor concordante à superfície $\mathrm{S}_{0}$ e aos limites do corpo. Nas extremidades leste e oeste, o bandamento magmático secundário e a foliação $\mathrm{S}_{1}$ são discordantes do bandamento primário $\left(\mathrm{S}_{0}\right)$. Ao desenvolvimento de dobras suaves a fechadas, de eixo subhorizontal e direcão geral E-W se associa uma foliacão de plano axial $\left(\mathrm{S}_{1}\right)$. Na parte norte do maciço a foliação segue uma direção N-S a N15E e mergulhos altos, ora para este, W-NW e ora para E-SE. As lineações são pouco desenvolvidas comparativamente à estruturação planar. Por vezes ocorrem biotita-hornblenda monzogranitos com ocelos quartzo-feldspáticos que apresentam um bandamento $\mathrm{S}_{0}$ subhorizontal proeminente, o qual é afetado por uma foliação de plano axial $\left(\mathrm{S}_{1}\right)$ subvertical, marcada pelo alongamento dos ocelos. Na escala microscópica, podem ser observadas bandas de cisalhamento conjugadas subverticais $(\mathrm{C}$ e $C^{\prime}$ ) (cf. Gapais et al. 1987) dispostas em pequenos ângulos com relação à superficie $\mathrm{S}_{1}$.

Os monzogranitos são cortados por pegmatitos e aplitos em veios e diques concordantes, longitudinais, transversais e diagonais ( $c f$. Balk 1937). Por vezes, em um mesmo afloramento, veios pegmatóides precoces fortemente deformados coexistem com veios tardios pouco deformados.

Zonas miloníticas/ultramiloníticas $\left(\mathrm{S}_{\mathrm{m}}\right)$ subverticais e larguras decimétricas a métricas são observadas dentro do Complexo Granítico Estrela. A foliação milonítica é marcada pela alternância de níveis muito finos ricos em minerais ferromagnesianos com finos níveis quartzo-feldspáticos. Nestas zonas, a foliação é muito mais desenvolvida do que as lineações $(\mathrm{S}>>\mathrm{L})$. A orientação destas zonas é 


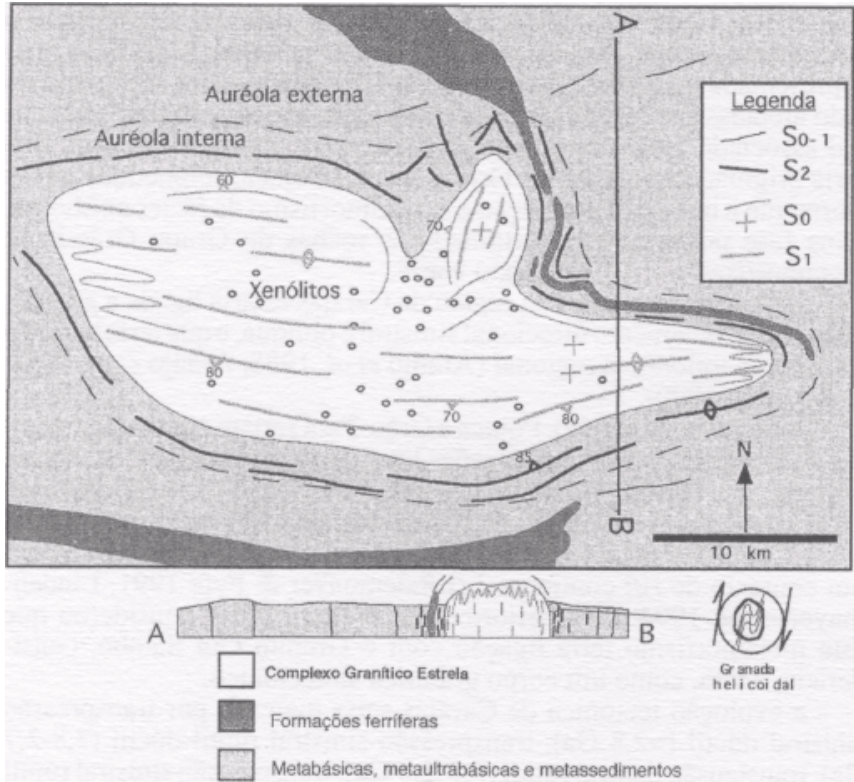

Figura 3-Mapa geológico do Complexo Granítico Estrela e de suas rochas encaixantes.

geralmente E-W/subvertical, sendo geralmente concordante à foliação $\left(\mathrm{S}_{1}\right)$, As lineações apresentam ângulos de caimento variáveis, geralmente baixos (subhorizontal a $20^{\circ}$ ) mas que podem atingir até $45^{\circ}$.

Caracterização Petrográfica e Química As rochas do Complexo Granítico Estrela são cinza claro, médias a finas e de composição predominante monzogranítica, subordinadamente tonalítica, granodiorítica e sienogranítica. Dentre os monzogranitos são distinguidos, com base nos minerais ferromagnesianos, as seguintes fácies: hornblenda monzogranitos, clinopiroxênio-hornblenda monzogranitos; biotita-hornblenda monzogranitos; biotita-hornblenda monzogranitos com ocelos de ilmenita; hornblenda-biotita monzogranitos e biotita monzogranitos (Barros 1991, Barros et al. 1997). Os termos ricos em hornblenda se concentram preferencialmente na porção oriental do maciço; na parte central ocorrem as rochas com hornblenda e biotita e, na centro-oeste, predominam os termos com biotita (Barros 1997, Barros et al. 1997). A mineralogia acessória é constituída de allanita, zircão, ilmenita e apatita.

O Complexo Granítico Estrela (Tabela 1) possui altas razões $\left[\left(\mathrm{K}_{2} \mathrm{O}+\mathrm{Na}_{2} \mathrm{O}\right) / \mathrm{CaO}=1,81-5,23\right],[\mathrm{FeOt} /(\mathrm{FeOt}+\mathrm{MgO})=0,93-0,99] \mathrm{e}$ altas concentrações de Y (13-404), Zr (146-640), Nb (21-45) e Ga (23-29) (Barros 1991, Jorge-João et al. 1991, Barros et al. 1997). Os teores de $\mathrm{Al}_{2} \mathrm{O}_{3}$ de monzogranitos ricos em biotita e fracamente peraluminosos são de $\sim 13,5 \%$, contrastando com os teores de $\sim 11,5 \%$ dos monzogranitos ricos em anfibólio e metaluminosos (Barros et al. op. cit.). Os monzogranitos possuem teores elevados de elementos terras raras (ZETR 374-993), cujo comportamento, comparado com o condrito (Evensen et al 1978), é marcado por um fracionamento fraco a moderado de ETR leves $\left[(\mathrm{La} / \mathrm{Sm})_{\mathrm{N}}=3,00-7,23\right]$, por um fracionamento desprezível de ETR pesados $\left[(\mathrm{Gd} / \mathrm{Yb})_{\mathrm{N}}=1,04-2,33\right] \mathrm{e}$ por anomalias negativas de európio $\left(\mathrm{Eu} / \mathrm{Eu}^{*}=0,26-0,65\right)$ moderadas a fortes (Fig. 5).

As características geoquímicas do Complexo Granítico Estrela são comparáveis às dos granitos do tipo A proterozóicos e fanerozóicos (Whalen et al. 1987, Sylvester 1994), cuja origem é atribuída à fusão parcial de granulitos (Clemens et al. 1986, Creaser et al. 1991, Skjerlie \& Johnston 1993, Landerberger \& Collins 1996) ou de rochas metaígneas anidras em temperaturas próximas de $900^{\circ} \mathrm{C}$ (Cullers et al 1981, Anderson \& Bender 1989, Sylvester 1989). Magmas graníticos muito quentes possuem baixa viscosidade e são colocados em níveis crustais rasos (Clemens \& Mawer 1992).

SEQÜENCIA METAVULCANO-SEDIMENTAR Estrutura e Metamorfismo A caracterização da evolução estrutural e metamórfica das rochas metavulcano-sedimentares possibilitou compreender as suas relações com o Complexo Granítico Estrela, sendo definidos três grandes domínios: a auréola externa, a auréola interna e o conjunto de xenólitos (Fig. 3).

A AURÉOLA EXTERNA Na auréola externa a estrutura principal é definida pelo acamadamento litológico $\left(\mathrm{S}_{0}\right)$, o qual é marcado pelas cristas de formações ferríferas e de quartzitos, ressaltadas no relevo, alinhadas na direção E-W e intercaladas a rochas metabásicas e metraultrabásicas, cujo relevo é bastante arrasado.

As rochas metabásicas mostram granulação fina a média, localmente grossa, estrutura maciça e textura subofítica preservada mas que não guarda mais a mineralogia da rocha original. Os clinopiroxênios primários são transformados em pseudomorfos de actinolita \pm clorita. Os anfibólios exibem um zoneamento brusco definido pela bordas finas de Fe-pargasita e Fe-tschermakita verde oliva $\left(\mathrm{Fe}_{2} \mathrm{O}_{3}=17.37\right.$ $21,37 \% ; \mathrm{Al}_{2} \mathrm{O}_{3}=12,07-16,35 \% ; \mathrm{TiO}_{2}=0,25-0,59 \% ; \mathrm{K}_{2} \mathrm{O}=0,47-$ $0,93 \% ; \mathrm{XMg}=0,34-0,46)$, que contrastam com as partes internas actinolíticas verde pálidas $\left(\mathrm{Fe}_{2} \mathrm{O}_{3}=11,89-12,99 \% ; \mathrm{Al}_{2} \mathrm{O}_{3}=2,24\right.$ $2.86 \% ; \mathrm{TiO}_{2}=0,05-0,16 \% ; \mathrm{K}_{2} \mathrm{O}=0,00 \% ; \mathrm{XMg}=0,68-0,70$ ) (Figuras $6 a-b$, Tabela 2). Os teores de anortita do plagioclásio variam de modo significativo nas rochas metabásicas da auréola externa $\left(\mathrm{An}_{28}-\mathrm{An}_{75}\right)$. Em rochas com texturas ígneas preservadas, o plagioclásio pode mostrar um zoneamento normal, pronunciado, marcado por teores de $\mathrm{An}_{75}$ nos núcleos e de $\mathrm{An}_{35}$ nas bordas. Os minerais opacos ocorrem como cristais esqueletais de magnetita.

Localmente ocorre uma foliação $\left(S_{1}\right)$ discreta, de largura decimétrica a centimétrica, subvertical e de direção geral E-W (Fig. 3) Em rochas metabásicas, esta foliação $\left(S_{1}\right)$ é desenhada pela orientação preferencial de clorita e de agregados de epidoto. Em rochas metaultrabásicas esta superfície $\left(\mathrm{S}_{1}\right)$ é marcada pela orientação de biotita e clorita e, em quartzitos micáceos, pela orientação de níveis anastomosados de biotita-muscovita alternados a níveis ricos em quartzo.

Em alguns xistos ultramáficos da auréola externa, ocorrem porfiroblastos euédricos de tremolita dispostos aleatoriamente, ou paralelos à foliação $\left(\mathrm{S}_{1}\right)$. Em metapelitos situados a cinco quilômetros a sul do Complexo Granítico Estrela, esta foliação é timidamente desenvolvida e marcada pela orientação preferencial de finos cristais de biotita, sobre os quais se desenvolvem fenoblastos de muscovita dispostos aleatoriamente.

Próximo da auréola interna, as rochas metabásicas mostram texturas transicionais onde feicões originais, como ripas de plagioclásio, coexistem com indícios de recristalização inicial e de formação de uma foliação $\left(S_{2}\right)$, marcada pela incipiente orientação de anfibólio e ilmenita. Os anfibólios podem mostrar um zoneamento gradacional (Figuras 6c-d, Tabela 2). Os núcleos são actinolíticos $(\mathrm{FeO}=13,56-$ $13,88 \% ; \mathrm{Al}_{2} \mathrm{O}_{3}=2.67-3,44 \% ; \mathrm{TiO}_{2}=0,24-0,31 \% ; \mathrm{K}_{2} \mathrm{O}=0,06-0,12 \%$; $\mathrm{XMg}=0.65-0,67)$, as partes intermediárias são do tipo Fe-hornblenda e Mg-hornblenda $\left(\mathrm{FeO}=15.36-15,69 \% ; \mathrm{Al}_{2} \mathrm{O}_{3}=5,30-6,90 \% ; \mathrm{TiO}_{2}=\right.$ $\left.0,47-0,66 \% ; \mathrm{K}_{2} \mathrm{O}=0,23-0,53 ; \mathrm{XMg}=0,53-0,61\right)$ e as margens são formadas por Mg-hornblenda, Fe-pargasita ou Fe-tschermakita $(\mathrm{FeO}$ $=17,20-18,52 \% ; \mathrm{Al}_{2} \mathrm{O}_{3}=8,29-9,39 \% ; \mathrm{TiO}_{2}=0,87-0,96 \% ; \mathrm{K}_{2} \mathrm{O}=$ $0,57-0,66 ; \mathrm{XMg}=0,49-0,53)$. Uma evolução mineralógica similar permitiu a Laird \& Albee (1981) demonstrar o caráter progressivo do metamorfismo em rochas metabásicas.

A AURE OLA INTERNA A auréola interna, com aproximadamente 2 quilômetros de largura, é o envelope encaixante imediato ao Complexo Granítico Estrela. Nesta auréola as rochas metavulcano-sedimentares apresentam uma foliação $\left(S_{2}\right)$ fortemente desenvolvida, subvertical e cuja trajetória se amolda aos contornos do complexo granítico (Fig. 3). A esta foliacão se associa uma lineação subvertical de intensidade moderada a forte, marcada pela orientação preferencial de plagioclásio, anfibólio e biotita.

A norte do Complexo, as trajetórias de foliação podem exibir um comportamento mais complexo, sugerindo a presença de junções tríplices de foliacão ( $c f$. Brun \& Pons 1981, Pons et al. 1995). Nestes domínios, as rochas anfibolíticas e metaultramáficas podem exibir uma estrutura fortemente linear traduzida pela presença de tectonitos L. A nordeste do Complexo ocorrem dobras de interferência de dimensões quilométricas, delineadas sobretudo por formações ferríferas.

Uma feição bastante freqüente nesta auréola é a presença de veios de anfibólio que cortam rochas metabásicas. Estes veios possuem larguras milimétricas a centimétricas, e os cristais de anfibólio que os preenchem são geralmente subautomorfos e apresentam granulação grossa. Localmente ocorrem sistemas de fraturas en échelon também preenchidas por anfibólio grosso.

As rochas metabásicas da auréola estão bastante recristalizadas. A mineralogia é homogênea e constituída de Fe-pargasita (Fig. 6e, Tabela 2) $\left(\mathrm{FeO}=14,96-17,38 \% ; \mathrm{Al}_{2} \mathrm{O}_{3}=7,75-10,94 \% ; \mathrm{TiO}_{2}=0,46-0,61 \%\right.$; 


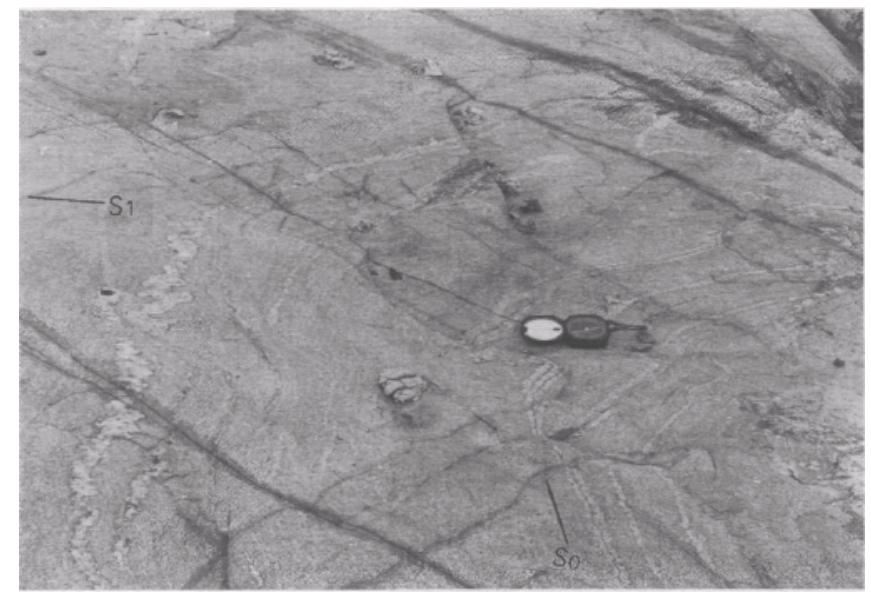

Figura 4-Afloramento da extremidade leste do Complexo Granítico Estrela mostrando bandamento magmático primário $S_{0}$ concordante com os limites do maciço, $O$ bandamento magmático é afetado por dobras de plano axial subvertical e de direção $E W$.

$\left.\mathrm{K}_{2} \mathrm{O}=0,30-0,80 ; \mathrm{XMg}=0,50-0,58\right)$ ou $\mathrm{Mg}$-hornblenda $\mathrm{FeO}=15,93$ $16,73 \% ; \mathrm{Al}_{2} \mathrm{O}_{3}=9,57-9,67 \% ; \mathrm{TiO}_{2}=0,52-0,73 \% ; \mathrm{K}_{2} \mathrm{O}=0,43-0,47 \%$; $\mathrm{XMg}=0,53-0,55)$, oligoclásio a labradorita (An23-62), por vezes biotita e diopsídio $(\mathrm{En}=31,40-34,50 \%$; Fs $=17,40-21,30 \%$; Wo= $46,20-49,40 \%$ ). Os minerais acessórios são cummingtonita, escapolita, ilmenita, apatita e allanita. A Fe-pargasita apresenta aspecto homogêneo e é verde oliva a verde acastanhado escuro. A boa orientação preferencial dos cristais resulta em uma textura granonematoblástica (Fig. 6f).

Nas formações ferríferas podem ser encontrados níveis ricos em moscovita bem desenvolvida e disposta aleatoriamente. Em metaultramáficas (anfibólio xistos) a mineralogia passa a ser dominada por finos cristais de tremolita, cuja forte orientação dá à rocha uma textura nematoblástica.

Junto ao contato norte do Complexo Granítico Estrela ocorrem, localmente, veios decamétricos de quartzo, com sulfetos, cortando rochas anfibolíticas. Um exemplo destes veios de quartzo ocorre na mina de ouro de Serra Verde, situada a menos de dois quilômetros do maciço granítico.

Próximo ao contato sul do Complexo Estrela ocorrem quartzo-plagioclásio-anfibólio-biotita gnaisses ricos em porfiroblastos de granada. Estas rochas mostram uma foliação marcante (N85E/85NW) desenhada pela forte orientação de anfibólio, plagioclásio e biotita. Uma lineação $(85 / 330)$ bem desenvolvida é marcada pela orientação da biotita. A presença de inclusões helicíticas nos porfiroblastos de granada (Paterson et al. 1989, Passchier \& Trouw 1996) denotam o seu caráter sintectônico e indicam uma movimentação inversa para sul da auréola interna com relação à externa (Fig. 3).

Junto ao contato sul do Complexo ocorrem mobilizados aplíticos esbranquiçados que englobam fragmentos de rocha máfica com bordas de reação verde-escuras, provavelmente constituída de Fe-pargasita, que contrasta com a coloração verde clara das partes internas, provavelmente de composição actinolítica.

OS XENÓLITOS Dentre os xenólitos (Fig. 3) do Complexo Granítico Estrela predominam os anfibolíticos comparativamente aos de metassedimentos. A disposição geográfica desses coincide, muitas vezes, com os limites de fácies petrográficas do complexo. Em geral, as rochas desta zona são maciças. Veios de anfibólio, similares às da auréola interna, podem ser abundantes em xenólitos anfibolíticos.

A mineralogia dos anfibolitos desta zona é constituída de andesinalabradorita (An49-61), anfibólio castanho do tipo Fe-pargasita, Feedenita, Fe-tschermakita e Fe-edenita (Fig. 6h, Tabela 2) $(\mathrm{FeO}=$ 14,24-26,08\%; $\mathrm{Al}_{2} \mathrm{O}_{3}=9,04-11,54 \% ; \mathrm{TiO}_{2}=0,43-1,65 \% ; \mathrm{K}_{2} \mathrm{O}=$ $0,50-1,44 ; \mathrm{XMg}=0,35-0,45)$, diopsídio $(\mathrm{En}=34,08-34,11 \% ; \mathrm{Fs}=$ $\left.18,48-21,30 \% ; \mathrm{Wo}_{0}=47,33-44,58 \%\right)$. Biotita castanho avermelhada, e ilmenita podem ocorrer em quantidades acessórias. Estas rochas exibem uma textura granoblástica desenhada por cristais de contatos retilíneos, os quais formam junções tríplices com ângulos próximos de $120^{\circ}$, resultando em arranjos poligonais e que evidenciam uma forte recristalização estática (Fig. 6g).

Caracterização Petrográfica e Química As seqüências metavulcano-sedimentares encaixantes do Complexo Granítico Es-

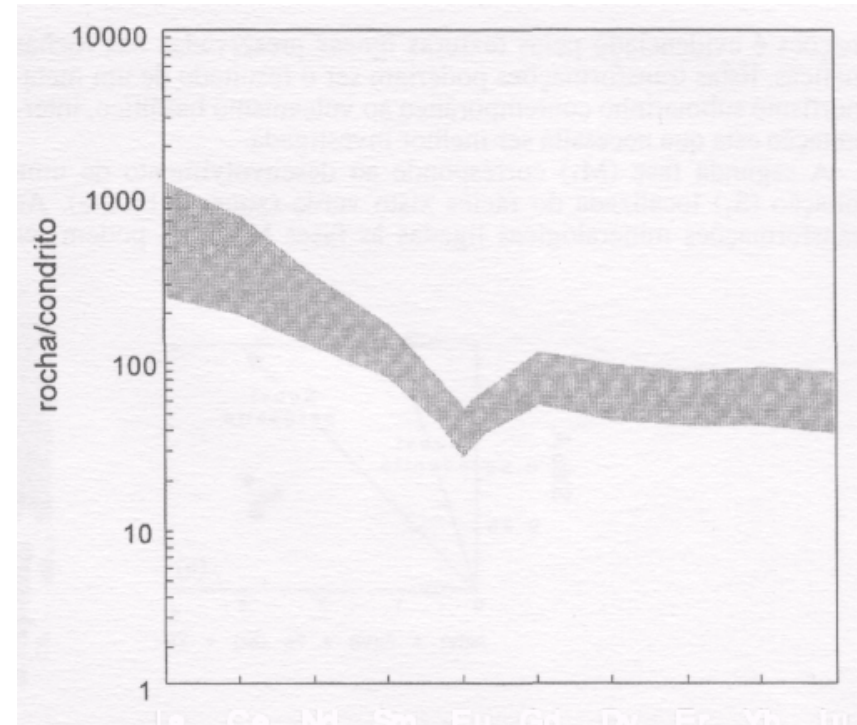

La $\mathrm{Ce} \mathrm{Nd} \mathrm{Sm} \mathrm{Eu} \mathrm{Gd}$ Dy $\mathrm{Er} \mathrm{Yb} \mathrm{Lu}$

Figura 5-Diagrama de elementos terras raras (normalisadas ao condrito de Evensen et al. 1978) do Complexo Granítico Estrela.

trela são constituídas de rochas metabásicas com intercalações de formações ferríferas bandadas e quartzitos, subordinadamente níveis de xistos ultramáficos, metapelitos, quartzo-micaxistos e rochas calcissilicáticas.

As rochas metabásicas (Tabela 3$)$ mostram teores médios $(0,41$ $0,63 \%)$ a elevados $(1,81-1,87 \%)$ de $\mathrm{K}_{2} \mathrm{O}$, concentracões altas de $\mathrm{Fe}_{2} \mathrm{O}_{3}$ $(13,01-16,42 \%)$ e moderadas de $\mathrm{MgO}(4,63-6,59 \%)$, teores de $\mathrm{SiO}_{2}$ entre 47,65 e $54,14 \%$ e de $\mathrm{Al}_{2} \mathrm{O}_{3}(14,24-14,96 \%)$ relativamente homogêneos. Os teores de $\mathrm{Cr}$ (123-357 ppm), Ni (65-177 ppm) e Co (40-500 ppm) são relativamente baixos, ao passo que os de $\operatorname{Zr}$ (54-186 ppm), Y (23-37 ppm) e de V (183-339 ppm) são moderados a altos. As concentracões dos ETR são 13 a 24 maiores que às do condrito de Evensen et al. (1978). O espectro dos ETR é muito pouco fracionado tanto nos ETR pesados $\left[(\mathrm{La} / \mathrm{Sm})_{\mathrm{N}}=1,18-4.05\right]$ quanto nos ETR leves $\left[(\mathrm{Gd} / \mathrm{Yb})_{\mathrm{N}}=1,16-1,77\right]$. As anomalias de európio $\left(\mathrm{Eu} / \mathrm{Eu}^{*}=0,94-1,09\right)$ são desprezíveis (Fig. 7). Estas características permitem comparar tais rochas com basaltos e basaltos andesíticos subalcalinos ( $c f$. Irvine \& Baragar 1971), ou com basaltos toleíticos ricos em ferro de terrenos do tipo greenstone (Arndt et al. 1977, Blais 1989, Cattel \& Taylor 1990, Condie1994).

DISCUSSÃO A natureza das rochas encaixantes do Complexo Granítico Estrela As encaixantes do Complexo Granítico Estrela são representadas por rochas metabásicas, com intercalações de formações ferríferas e quartzitos, e lentes de mica-xistos, metapelitos, xistos ultramáficos, e mais raramente de rochas calcissilicáticas. A assinatura toleítica rica em ferro dos metabasaltos é similar a de outros greenstone-belts. Logo, as seqüências Salobo, Pojuca, Luanga, Rio Novo e Grão-Pará, parecem ser contemporâneas e constituir extensões laterais de um extenso greenstone belt (greenstone Rio Novo de Hirata et al 1982).

As rochas encaixantes situadas a sul e a norte do complexo granítico foram anteriormente correlacionadas a unidades lito-estratigráficas diferentes. Entretanto, as semelhanças litológicas e tectono-metamórficas das rochas metavulcano-sedimentares que envelopam o Complexo Granítico Estrela permitem considerá-las pertencentes à mesma unidade litoestratigráfica. As rochas fortemente deformadas, situadas imediatamente a norte do Complexo Granítico Estrela, antes consideradas como pertencentes ao Complexo Xingu são, na verdade, anfibolitos fortemente recristalizados da auréola tectônica do complexo granítico.

A evolução tectono-metamórf ica das rochas encaixantes do Complexo Granítico Estrela A história metamórfica das rochas metavulcano-sedimentares arqueanas encaixantes do Complexo Granítico Estrela é marcada por três fases dentro de um regime de metamorfismo progressivo, o qual é evidenciado pelas transformações estruturais, texturais e mineralógicas, principalmente das rochas metabásicas.

A primeira fase $\mathrm{M}_{0}$ é representada por transformações hidrotermais de condições de fácies xisto verde. $\mathrm{O}$ caráter estático destas transfor- 
mações é evidenciado pelas texturas ígneas preservadas nas rochas máficas. Estas transformações poderiam ser o resultado de um metamorfismo submarinho contemporâneo ao vulcanismo basáltico, interpretação esta que necessita ser melhor investigada.

A segunda fase $\left(\mathrm{M}_{1}\right)$ corresponde ao desenvolvimento de uma foliação $\left(\mathrm{S}_{1}\right)$ localizada do fácies xisto verde (zona de biotita). As transformações mineralógicas ligadas às fases $\mathrm{M}_{0}$ e $\mathrm{M}_{1}$ podem ser observadas na auréola externa. O lapso de tempo entre estas duas fases é ainda incerto.

A terceira fase $\left(\mathrm{M}_{2}\right)$ corresponde ao metamorfismo de contato provocado pelo Complexo Granítico Estrela. A partir das assembléias mineralógicas principalmente nas rochas metabásicas pode-se estimar um intervalo de temperatura de $\sim 450-550^{\circ} \mathrm{C}$ para a auréola externa, de $\sim 550-650^{\circ} \mathrm{C}$ para a auréola interna e de $\sim 650-850^{\circ} \mathrm{C}$ para os xenólitos.

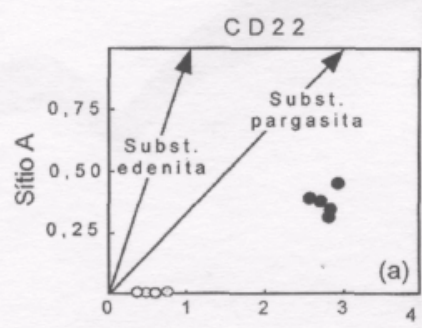

$\mathrm{Al}(\mathrm{IV})+\mathrm{Al}(\mathrm{VI})+\mathrm{Fe}(3+)+2 \mathrm{TI}$
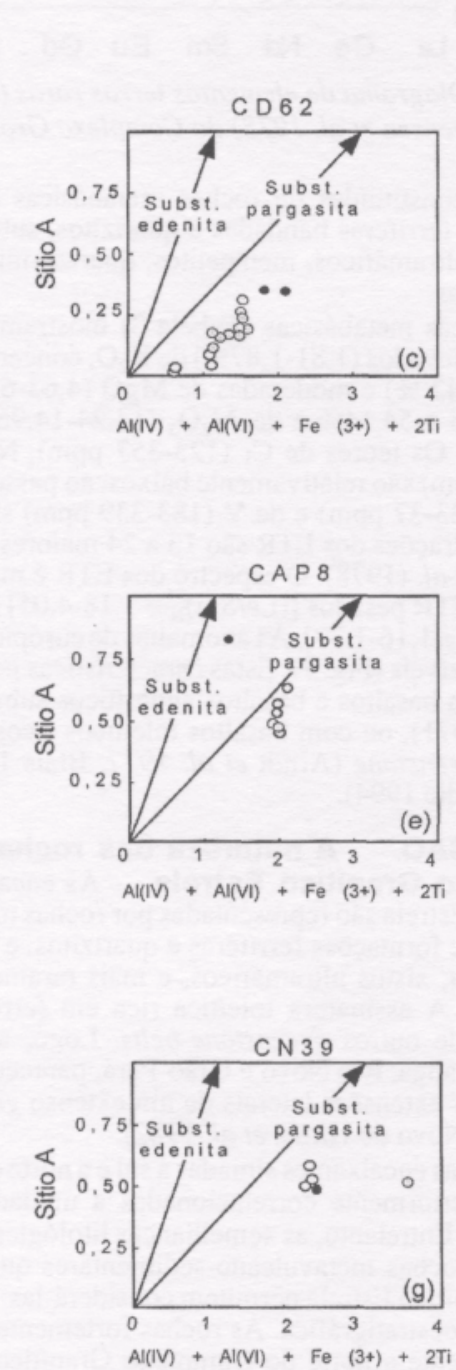

- centro do cristal

- parte intermediária do cristal

- borda do cristal

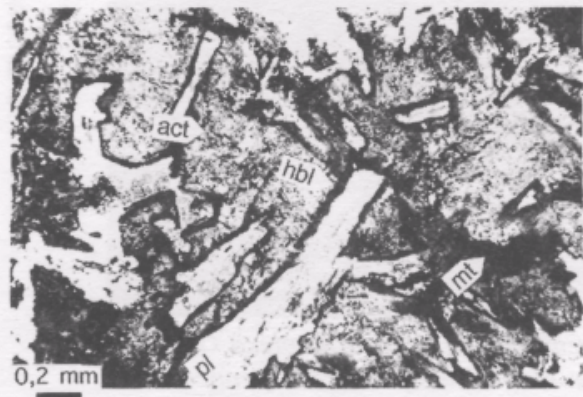

(b)

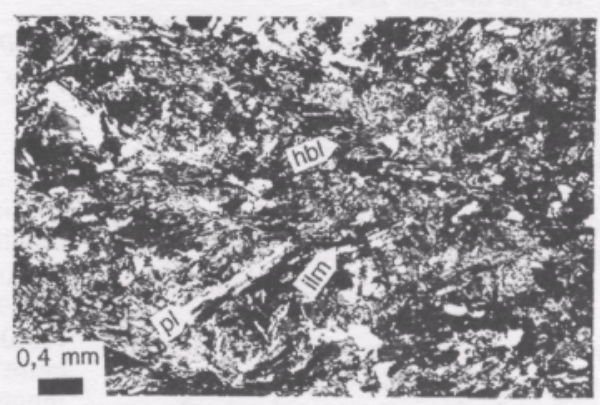

(d)

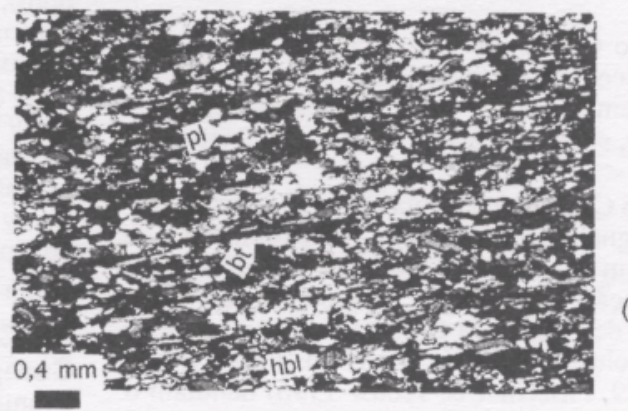

(f)

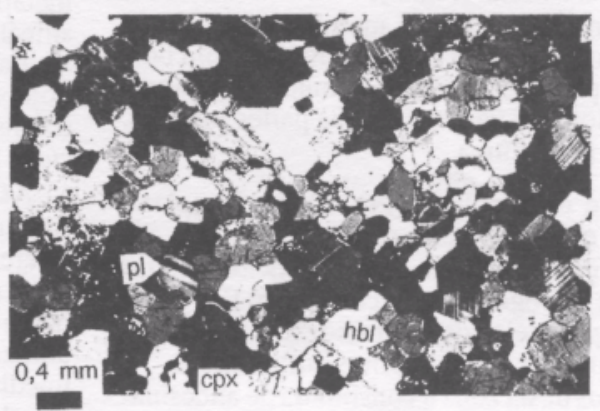

(h)

Figura 6-Fotomicrografias de lâminas delgadas de rochas metabásicas (act = actinolita; hbl $=$ hornblenda; $p l=p l a g i o c l a ́ s i o ; ~ c p x=$ clinopiroxênio; $b t=$ biotita $;$ ilm = ilmenita; $m t=$ inagnetita). (a) Rocha metabásica com textura ígnea preservada, (b) Diagrama Sítio A $x$ $A l^{(I V)}+A l^{(V I)}+F e^{(3+)}+2 T i$ de anfibólios de rocha metabásica com textura ígnea preservada, (c) Rocha metabásica com textura transicional. (d) Diagrama Sítio $A \times A l^{(I V)}+A l^{(V I)}+F e^{(+3)}+2 \mathrm{Ti}$ de anfibólios de rocha metabásica com textura transicional. (e) Rocha metabásica da auréola interna com textura granonematoblástica. (f) Diagrama Sítio $A \times A l^{(V)}+A l^{(V I)}+F e^{(3+)}+2 \mathrm{Ti}$ de anfibólios de rocha metabásica com textura granonematoblástica. (g) Rocha metabásica com textura granoblástica. (h) Diagrama Sítio $A x A l^{(V)}+A l^{(V I)}+F e^{(3+)}+2 \mathrm{Ti}$ de anfibólios de rochametabásica granoblástica. 
Tabela l-Dados químicos (elementos maiores e menores em \% de peso, elementos traço em ppm) representativos do Complexo Granítico Estrela.

\begin{tabular}{|c|c|c|c|c|c|c|c|c|c|c|c|c|c|}
\hline & \multicolumn{3}{|c|}{ 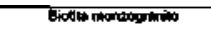 } & \multicolumn{3}{|c|}{ 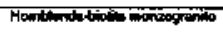 } & \multirow{2}{*}{ 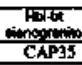 } & \multirow{2}{*}{ 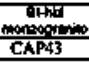 } & \multicolumn{2}{|c|}{ 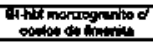 } & \multirow{2}{*}{ 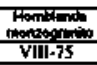 } & \multirow{2}{*}{ 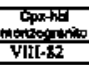 } & \multirow{2}{*}{ 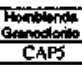 } \\
\hline & $\mid V m$ & CAPI4 & CAP31 & $\mathrm{CN}-\mathrm{A}$ & CAP39 & CAP33 & & & VI.62 & CAP13 & & & \\
\hline SHOL & 74,69 & 72,60 & 68,51 & 73,12 & 70,41 & 71,23 & 67,30 & 71,50 & 64,73 & 69,83 & 72.89 & 71,03 & 72,43 \\
\hline $\mathrm{TO}_{2}$ & 0.14 & 0.21 & 0,59 & 0.35 & 0,30 & 0.25 & 0,68 & 0.35 & 0,64 & 0,62 & 0.59 & 0,59 & 0,32 \\
\hline ABOS: & 13,36 & 13.06 & 11,39 & 13,64 & 1352 & 13.57 & 11.50 & 12.97 & 11,60 & 11,44 & II.K8 & 11.59 & 11,30 \\
\hline FenO3 & 1,19 & 3,91 & 9,34 & 1,67 & 4,41 & 4,31 & 9,33 & 4,40 & 3,42 & 8,32 & 2,34 & 1,59 & 6,08 \\
\hline $\mathrm{FeO}$ & 1,44 & & & 2.83 & & & & & 4,57 & & 3,81 & 3,23 & \\
\hline Mno & B.,01 & 0,02 & 0.04 & 0.00 & 0.04 & & 0.03 & 0,02 & 0.03 & 0.05 & 0,03 & 0.05 & 0,06 \\
\hline $\mathrm{MgO}$ & 0,06 & 0.24 & 0,16 & 0.12 & 0,37 & 0,23 & 0,34 & 0,23 & 0,24 & 0,19 & 0,11 & 0,04 & 0.12 \\
\hline $\mathrm{CHO}$ & 1.08 & 1,18 & 2,05 & 1,53 & 1,67 & 1,48 & 2,46 & 1,60 & 2,09 & 1,60 & 2,26 & 2,32 & 3,13 \\
\hline $\mathrm{NaxO}$ & 3.42 & 3,46 & 3,36 & 2,72 & 3,93 & $3 \leqslant 1$ & 1,96 & 3,21 & 2,96 & 3,22 & 3,69 & 3,45 & 4,09 \\
\hline$x \times 0$ & 4,65 & 4.21 & 2.83 & 3.92 & 3.63 & 4.23 & 5.20 & 4,68 & 4,25 & 3.46 & 2.58 & 4.05 & 1,59 \\
\hline $\mathrm{P} 2 \mathrm{OS}$ & 0,06 & 0,03 & 0,08 & 0,08 & 0,06 & 0,04 & 0,12 & 0,04 & 0.12 & 0,09 & 0.07 & 0,09 & 0.05 \\
\hline $\mathbf{P} F$ & 0,16 & 0,81 & 1,33 & 0,36 & 1,18 & 1,07 & 0,4 & 0,78 & 0,10 & 0,90 & 0,02 & 0,08 & 0,30 \\
\hline Tolal & 100,28 & 49.73 & 99,68 & 101.34 & 100.01 & 99,74 & 9956 & 99.80 & 100.15 & 59.72 & 100.17 & 98,42 & 99,67 \\
\hline$B_{1}$ & & 758 & 1557 & & 685 & 766 & $1 \% 68$ & 915 & & 650 & & & 860 \\
\hline $\mathrm{Ga}$ & & 23,9 & 28,5 & & 28,9 & 26,6 & 265 & 23,5 & & 23,5 & & & 26,6 \\
\hline $\mathbf{R t}$ & 233 & 185 & 397 & 267 & 196 & 160 & 170 & 258 & 168 & 102 & 40 & 117 & 53.5 \\
\hline se & 35 & $\$ 4,2$ & 16.8 & 64 & $58, \mathrm{n}$ & 56.1 & 41.7 & 60,1 & 47 & 14,8 & 47 & 92 & 72.5 \\
\hline $\mathrm{Nb}$ & 21 & 28,9 & 36,7 & 45 & 31,9 & 30,5 & 26,1 & 25,3 & 34 & 26,8 & 31 & 38 & 32 \\
\hline $\mathbf{z}$ & 146 & 291 & $\$ 77$ & 258 & 425 & 399 & 625 & 351 & 640 & 555 & 546 & 564 & 632 \\
\hline$\xi$ & 13 & 34,9 & 136 & 102 & $\mathbf{B O B}$ & $n, 4$ & 99,6 & 74 & 131 & 100 & 109 & 404 & 138 \\
\hline v & & 30 & 10,7 & & 67.3 & 43.6 & 6.35 & 26,4 & & 4.36 & & & 7.29 \\
\hline Ti & & 125 & 24,1 & & 222 & 136 & 25 & 161 & & 19.4 & & & 40,3 \\
\hline $\mathbf{P h}$ & & 25.5 & 6.43 & & 49,3 & 27,9 & s.34 & 36.4 & & 5.28 & & & 2.26 \\
\hline L & & 193,7 & 81,26 & & 281,5 & 2067 & $7 y, 23$ & 213,6 & & 30,02 & & & 138.2 \\
\hline $\mathrm{ce}_{\mathrm{e}}$ & & 320,6 & 152,3 & & 440,9 & $355 A$ & $\mathbf{t} \$ 8,1$ & 351,9 & & 143,4 & & & $28 t, 9$ \\
\hline Pr & & 32.9 & 17,43 & & 44,61 & 33.46 & 17,8 & 33,56 & & 16,69 & & & 32,91 \\
\hline Nd & & 110.1 & 67,49 & & 143,3 & 108,3 & 69,72 & $109 A$ & & 65,32 & & & 121,1 \\
\hline Sin & & 18,63 & 14,46 & & 23,53 & 17,92 & 15,31 & 17,29 & & 14,25 & & & 23,05 \\
\hline Eu & & 1,46 & 1,81 & & 1,87 & 1,53 & 3,26 & 1,34 & & 2,65 & & & 2,59 \\
\hline$G d$ & & 16,73 & 15,49 & & 20,32 & 15,62 & 14,76 & 14,36 & & 14,93 & & & 22,16 \\
\hline th & & 2,37 & 2,65 & & 2,67 & 2,28 & 257 & 2,19 & & 2,48 & & & 3,56 \\
\hline Dy & & 14,07 & 17,06 & & 14,34 & 13,04 & 16,36 & 12,71 & & 16,13 & & & 22,84 \\
\hline Ho & & 3,05 & 4.18 & & 2,84 & 2,77 & 3,8 & 2.71 & & 3.7 & & & 5.01 \\
\hline $\mathrm{Er}$ & & 7.59 & 11,62 & & 7,62 & 7.56 & 9,97 & 6.93 & & 10,35 & & & 13.55 \\
\hline Tm & & 1,2 & 1.79 & & 1,04 & 1,07 & $(1,51$ & I,II & & 1.58 & & & 2,06 \\
\hline Yb & & 7,82 & 12,04 & & 705 & 731 & 10.59 & 6,76 & & 10,63 & & & 14,71 \\
\hline 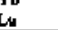 & & $\begin{array}{l}1,102 \\
1,18\end{array}$ & 1,89 & & 1,11 & 1,05 & 1,58 & 0,95 & & $\begin{array}{l}1.613 \\
.61\end{array}$ & & & 2,13 \\
\hline
\end{tabular}

Tabela 2-Dados químicos (em \% de peso) representativos de anfibólios de rochas metabásicas encaixantes do Complexo Granítico Estrela.

\begin{tabular}{|c|c|c|c|c|c|c|c|c|c|c|c|c|c|c|c|c|}
\hline \multirow{3}{*}{\begin{tabular}{|l} 
\\
Amodin \\
Postipla mo \\
angtal
\end{tabular}} & \multirow{2}{*}{\multicolumn{3}{|c|}{ Ainsolotentims }} & \multirow{2}{*}{\multicolumn{3}{|c|}{ 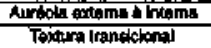 }} & \multicolumn{6}{|c|}{ Anogle nitum } & \multicolumn{4}{|c|}{$x \operatorname{sen} 6 \sin x$} \\
\hline & & & & & & & \multicolumn{6}{|c|}{ 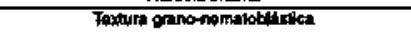 } & \multicolumn{4}{|c|}{ 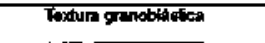 } \\
\hline & $\frac{\cos x}{\text { borda }}$ & $\frac{6022}{\text { bondile }}$ & conth & $\frac{\operatorname{CDA2}}{\text { bont }}$ & $\begin{array}{l}\text { CDBS } \\
\text { intomm. }\end{array}$ & $\frac{\operatorname{CDS2}}{\operatorname{con} 61 \text { ro }}$ & $\frac{\text { CAP' } 8}{\text { Cenhor }}$ & $\frac{C A P^{8}}{\text { Condro }}$ & $\frac{\text { CAP } \theta}{\text { candro }}$ & $\frac{C A P \cdot 8}{\text { Intam. }_{1}}$ & $\frac{\cos 20}{\operatorname{con} 0}$ & $\frac{\cos 20}{\operatorname{con} 10^{\circ}}$ & $\frac{\text { CN39 }}{\text { bondt }}$ & $\frac{\text { CN } 39}{\text { hinom. }}$ & $\frac{\text { CHiga }}{\text { centiro }}$ & $\frac{\text { CN39 }}{\operatorname{con} 100}$ \\
\hline S101 & 39,55 & 4,52 & 53,24 & 67,055 & $\$ 0,59$ & Sב,B1 & 41,36 & $\$ 1,38$ & 41,06 & 42,22 & 46,23 & 45,35 & 42,72 & 42,30 & 42,19 & 2,03 \\
\hline Altos & 16,35 & 14,05 & 2,86 & 8,24 & 5,30 & 2,67 & 9,65 & 9.42 & 9,46 & 9,80 & 9,60 & 9,59 & 11,13 & 11,28 & 11,23 & 992 \\
\hline THO & 0,40 & 0.33 & 0.12 & 0.82 & 0.47 & 0,29 & 1,42 & 1,35 & 1.22 & 1,13 & 0,66 & 0,73 & 1,51 & 1.65 & 1,61 & 131 \\
\hline FeO & 18,04 & $17, \mathrm{B3}$ & 12,27 & 17,03 & IS, $\theta$ P & (13,8y & 23,33 & 22,80 & 22,80 & 23,05 & 16,73 & 15,43 & 18,53 & 19.15 & 19,47 & 18,97 \\
\hline Mno & 0,20 & 0,04 & 0,02 & 0,08 & 0.26 & 0,21 & 0,00 & 0.00 & 0,11 & 0,08 & 0,17 & 0.30 & 0,18 & 0.22 & 0.16 & 0,22 \\
\hline MgO & 6,51 & 8,42 & 15,608 & 10,81 & 13,80 & 15,41 & 7,34 & 6,94 & 704 & 687 & 11,07 & 11,17 & 8,37 & 7,59 & 7,80 & 367 \\
\hline $\operatorname{CoO}$ & 11,62 & 1191 & 11,96 & 11,69 & 11,91 & $11,9 \mathrm{gg}$ & 10,82 & 10,70 & 10,94 & 11,29 & 11,08 & 11,21 & 11,61 & 11,50 & 1153 & 11,66 \\
\hline $\mathrm{Cr}_{2} \mathrm{O}$ & 0.00 & 0.27 & 0.06 & 003 & 0,06 & 000 & 000 & 001 & 0,00 & 0,05 & 0,00 & 0,00 & 0,00 & 0,01 & 0,06 & 0.08 \\
\hline NIO & 0,22 & 0,07 & $0+18$ & 0,00 & 0,15 & 0,00 & $0 ; \infty$ & 0,00 & 0,04 & 0,04 & 0,00 & 0,02 & 0,05 & 0,07 & 0,00 & 0,05 \\
\hline NaO & 1,59 & 1,23 & 0,24 & 1,02 & 0,54 & 0,39 & $\mathbf{1 , 8 9}$ & 1,76 & 1,78 & 1,74 & 136. & ing & 1,60 & $1, n$ & 183 & 1,49 \\
\hline & & $0, \$ 7$ & 0,00 & 0,40 & 0.23 & 0,10 & 1,23 & 1,35 & 1,27 & 1,46 & 0,43 & 0,47 & 0,84 & 0,91 & 095 & 0,91 \\
\hline TOTAL & 95.113 & 97.12 & 96,69 & 97.17 & 48.38 & 97.71 & 9205 & 96.21 & 96,72 & 97.74 & 97,34 & $\boldsymbol{4 6 . 1 9}$ & 96,78 & 96,46 & $\mathbf{9 6 8 3}$ & 45,31 \\
\hline \multicolumn{17}{|c|}{ 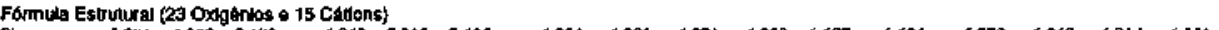 } \\
\hline & 5,891 & 6,392 & $7,6,42$ & 6,869 & 7,312 & 7,6035 & 6,224 & 6,281 & $6,27 \mathrm{I}$ & 6,230 & 6,687 & $0,6,624$ & 6,272 & 6,208 & 6,214 & 6,551 \\
\hline w) & 2.109 & 1,608 & 0,390 & 1,137 & $0 \times 888$ & 0,365 & $1,67 !$ & 1.6ins & 1,602 & 1,704 & & & 17 & & & 1,449 \\
\hline & 8,000 & 8,000 & 8,000 & 8000 & 8,000 & 8,000 & 7.895 & $7,4,46$ & $7,93,3$ & 7,434 & 8000 & 8000 & 8.000 & 8.000 & 8000 & 8,000 \\
\hline VI) & $0,76 \mathbf{3}$ & 0,80 & 0,179 & 0,2 & 0,214 & 0,0 & 0000 & 0,000 & 0,000 & $0,00 \mathrm{OH}$ & 0,323 & 0,273 & 0,148 & 0,238 & 3 & 0,373 \\
\hline 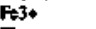 & 0,000 & 0.155 & 0,000 & 0,000 & 0.139 & & 0,000 & & & & & & & & & \\
\hline$\pi$ & 0,045 & 0.037 & 0,013 & 0,000 & $0.0 \mathrm{~s} 1$ & 0,032 & 0,157 & $0, \mathrm{t52}$ & 0.137 & 0,125 & 0,072 & 0,080 & 0.167 & 0,184 & 0.178 & 0,154 \\
\hline $\mathrm{Cr}$ & 0,000 & 0,031 & 0,007 & 0,003 & 0,007 & 0,000 & 0,000 & 0,001 & 0,000 & D,0O6 & 0,000 & 0,000 & 0,000 & 0,001 & 0,007 & 0,010 \\
\hline $\mathrm{Mi}$ & 0,027 & 0,009 & 0,021 & 0,000 & 0,017 & 0,000 & b,000 & 0.000 & 0,005 & 0,005 & 0000 & 0,009 & $0,0.11$ & 0,008 & 0,000 & 0,006 \\
\hline WF & $1.4 \pi$ & I $A 34$ & 3,377 & 2,350 & 2972 & 3,321 & 1,610 & 1.551 & 1,569 & 1,502 & 2.355 & 2,430 & 1.832 & 1.676 & 1.72 & 2,014 \\
\hline$F=2+$ & 2,745 & 20086 & 1.491 & 2,179 & 1.757 & 1,541 & 3,021 & 3.014 & 2,995 & 3,003 & 2,087 & 2,009 & $2, \mathbf{3 6 3}$ & 2,485 & 2,516 & 2,358 \\
\hline Men & 0,025 & 0,005 & 0,003 & 0,010 & 0,032 & 0,023 & 0,000 & 0,000 & 0,054 & 0,010 & 0,020 & $0,0,7$ & 0,022 & 0,028 & 0,020 & 0,029 \\
\hline $\mathrm{c}$ & 4,653 & 5,090 & 5,091 & 4,862 & $5,18 x$ & 5,144 & $4,7 \mathrm{kB}$ & 4.719 & 4,715 & 4,651 & 4837 & 4.833 & 4,612 & 4020 & 4,597 & $5,0 \% 9$ \\
\hline & I,f5s & 1919 & 1,8 & 4 & 1,824 & 1,8 & 1,700 & 1,719 & $I_{4}$ & $b_{1}$ & 1.7 & 1,7 & 6 & 1.826 & 1,220 & 1,447 \\
\hline & 0 & 001 & & 0,1 & 0.150 & 0.1 & 0.297 & 0.281 & 0,253 & 0.215 & 0.283 & 0,248 & 0,174 & 0,174 & 0,180 & 0,053 \\
\hline & 2,000 & 2000 & 1,918 & 2,000 & 1,974 & $1,9 / 4$ & $2, \mathrm{MaO}$ & 2,000 & 2,000 & 2,000 & 2,000 & 2,000 & 2,000 & 2,000 & 2,000 & $2 ; 000$ \\
\hline (A) & 0,314 & $a$ & 0.0 & 0,114 & o, & 0 & 0,242 & 0,231 & 0 & 0,297 & 0,0 & 0, & 0,3 & 0.3 & 0,3 & 0,3 \\
\hline & 0,129 & ons9 & 0,000 & 0,075 & 0,043 & 0,01 & 0,231 & 0,254 & 0,242 & 0,275 & 0,079 & 0,087 & 0,157 & 0,172 & 0,178 & 0,181 \\
\hline & 0,443 & 0,368 & & 0,189 & 0,043 & 0,018 & 0,472 & 0,489 & 0,504 & 0,572 & 0.176 & 0.232 & 0,49 & 0.492 & 0.521 & 0,578 \\
\hline L & 15,006 & $15,45 \pi$ & 15,009 & 13,051 & 15,210 & 13,126 & 15,155 & 15,159 & 15,152 & IS,159 & 16,726 & 15,005 & 15,108 & 15,112 & 15,118 & 15,638 \\
\hline $\mathbf{X M}$ & 10.382 & 0.457 & 0,644 & 0,523 & 0,610 & $0,6+5$ & (1) 348 & 0.340 & 0.343 & $(0,333$ & ff.533 & 0).547 & 0,435 & 0.403 & 0,405 & 0,469 \\
\hline
\end{tabular}

A formação da auréola interna (foliação $S_{2}$ ) é uma resposta ao aumento da ductilidade das rochas metavulcano-sedimentares, provocado pelo aumento dos gradientes termais, assim como pela deformação induzida pelo inchamento (ballooning) (cf. Bateman 1985) do complexo granítico somado ao encurtamento horizontal regional de direção N-S. Os efeitos da auréola tectônica somados à deformação regional deram origem a dobras de interferência de grande escala que afetam, sobretudo, faixas de formações ferríferas situadas a leste e a nordeste do complexo granítico.

O modelo de evolução metamórfica, proposto acima, permite descartar a idéia de separação de unidades litológicas da seqüência metavulcano-sedimentar arqueana de Carajás com base em diferenças de grau metamórfíco. Estas conclusões se assemelham às de Lindenmayer
\& Fyfe $(1991,1992)$ sobre o alvo do Salobo, situado mais a oeste da área estudada.

A posição estratigráfica do Complexo Granítico Estrela

Durante muito tempo perdurou a dúvida sobre a posição estratigráfica e a evolução petrológica do Complexo Granítico Estrela e das rochas metavulcano-sedimentares arqueanas da região de Carajás. Um problema de taxionomia foi criado em torno do maciço Estrela. A presença de feições deformacionais, estimulou Araújo et. ai. (1988) e Costa et al. (1990) a considerar o maciço como um conjunto de gnaisses pertencentes ao Complexo Xingu. Barros \& Dall'Agnol (1994) passaram a considerá-lo como um corpo granítico deformado de modo heterogêneo, intrusivo em rochas metavulcano-sedimentares (Barros 


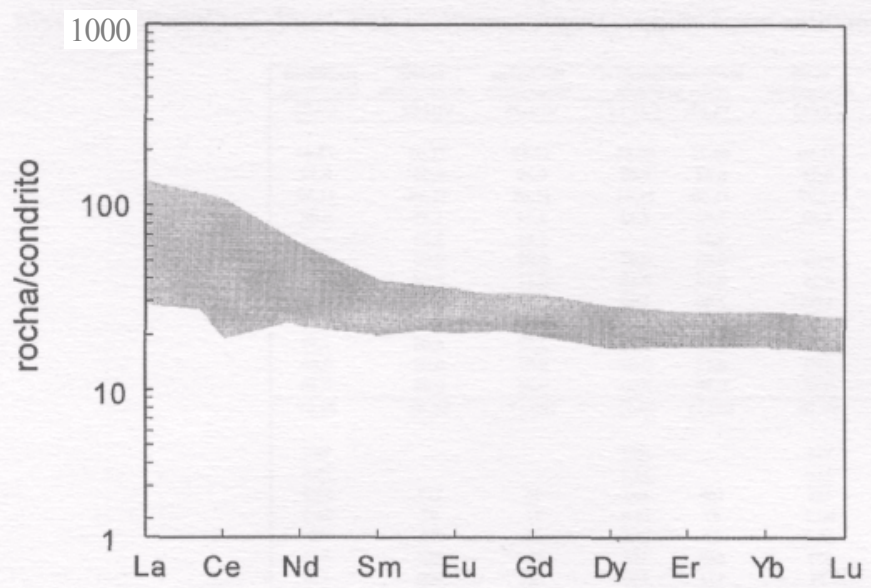

Figura 7. Diagrama de elementos terras rams normalisadas ao condrito de Evensen et al. (1978) das rochas metabdsicas encaixantes do Complexo Granitico Estrela.

1991, Barros et al. 1992). Esta ultima hipotese e confirmada (Barros 1997, este trabalho) com a demonstração dos efeitos de contato do Complexo sobre as rochas encaixantes, pela historia deformacional de sua colocação e pela evolução petrológica de suas rochas.

A idade Rb-Sr (rocha total) do Complexo Granitico Estrela A idade de $2527 \pm 34 \mathrm{Ma}$ (Rb-Sr rocha total) do Complexo Granitico anteriormente considerada como uma idade minima, foi comparada por Barros (1997) a idade de $2567 \mathrm{Ma}$ (U-Pb em zircões) das rochas do Granito Old Salobo (Machado et al. 1991, Souza 1996). A semelhança petrográfica, geoquímica e estrutural destes dois corpos graníticos, assim como a semelhança da evolução metamórfico-estrutural de suas respectivas rochas encaixantes, sugerem fortemente que ambos pertençam ao mesmo episódio magmático. Caso se confirme esta contemporaneidade, poder-se-a dizer que o comportamento do sistema $\mathrm{Rb}$-Sr nestas rochas difere do observado em outros granitoides arqueanos, principalmente os situados mais ao sul, na regiao de Rio Maria, onde as idades $\mathrm{Rb}-\mathrm{Sr}(\sim 2,5 \mathrm{Ga})$ são bem menores do que as idades U-Pb em zircão (2,87 a 2,97 Ga) (Macambira \& Lafon 1995). Ao que tudo indica, estes granitoides alcalinos tardi-arqueanos foram os responsáveis pela reabertura do sistema $\mathrm{Rb}-\mathrm{Sr}$ na região de Carajás.

A formalização da denominação Complexo Granitico Estrela A distribuição de fácies petrográficas tern permitido individualizar domínios relativamente bem demarcados dentro do maciço granítico, como mostra a ampla predominância de hornblenda monzogranitos e de biotita monzogranitos, respectivamente a leste e a oeste do corpo. Este contraste composicional e refletido claramente pelos dados geoquímicos (rochas metaluminosas e fracamente peraluminosas). A concordância entre os limites das diferentes fácies petrográficas com as trajetórias de foliação e com a forma do corpo, particularmente na parte norte do maciço, onde a foliação tem direção N-NE. Cartas aerogeofísicas (Andrade 1991) confirmam a existência de diferentes domínios cujos limites se aproximam bastante dos inferidos pelos critérios mencionados anteriormente. Um pouco menos nítida $\mathrm{e}$ a distribuição espacial dos xenólitos ao longo dos limites de fácies petrográficas. Estes diferentes domínios evidenciam a presença de diferentes plútons dentro do maciço Estrela. Isto, combinado ao fato de que muitas vezes se observam afloramentos onde rochas petrograficamente diferentes se intercalam de modo heterogêneo, permite utilizar a denominção "complexo".

\section{A evolução estrutural do Complexo Granitico Estrela}

Padrões concêntricos de foliações magmáticas de corpos graníticos, delineados por foliações subverticais na periferia e subhorizontais nas partes centrais dos plutons sao interpretadas por Gapais (1989) como o resultado dos efeitos de escoamento divergente promovido pelo inchamento (ballooning) dos plútons (Bateman 1984, Castro 1987). A arquitetura dômica do Complexo Granítico Estrela desenhada pelas trajetorias das foliações magmáticas $\left(\mathrm{S}_{0}\right)$ e uma resposta a este mecanismo. Em alguns locais, a modificação da orientação da foliação parece indicar a interferência exercida por plútons diferentes, os quais teriam-se moldado um contra o outro durante a colocação sintectônica.
Tabela 3 - Dados químicos (elementos maiores e menores em \% de peso, elementos traço em ppm) representativos das rochas metabásicas encaixantes do Complexo Granítico Estrela.

\begin{tabular}{|lccccc|}
\hline & $\mathrm{CD} 65$ & $\mathrm{CN} 39$ & $\mathrm{CRN} 32$ & $\mathrm{CD} 66$ & $\mathrm{CAP} 3$ \\
\hline $\mathrm{SiO} 2$ & 48,72 & 47,65 & 47,99 & 48,26 & 54,19 \\
$\mathrm{Al} 2 \mathrm{O}_{3}$ & 14,24 & 14,9 & 14,96 & 14,3 & 14,81 \\
$\mathrm{Fe} 2 \mathrm{O} 3$ & 16,42 & 14,75 & 13,01 & 15,89 & 15,73 \\
$\mathrm{MnO}$ & 0,23 & 0,19 & 0,21 & 0,22 & 0,25 \\
$\mathrm{MgO}$ & 4,85 & 6,59 & 6,52 & 5,75 & 4,63 \\
$\mathrm{CaO}$ & 7,74 & 11,06 & 12,47 & 10,31 & 4,46 \\
$\mathrm{Na} 2 \mathrm{O}$ & 2,48 & 2,45 & 2,56 & 2,55 & 1,58 \\
$\mathrm{~K} 2 \mathrm{O}$ & 1,87 & 0,54 & 0,63 & 0,41 & 1,81 \\
$\mathrm{TiO} 2$ & 1,79 & 0,98 & 0,86 & 1,28 & 1,15 \\
$\mathrm{P} 2 \mathrm{O} 5$ & 0,22 & 0,12 & 0,14 & 0,17 & 0,29 \\
$\mathrm{H} 2 \mathrm{O}$ & 1,19 & 0,59 & 0,41 & 0,67 & 0,61 \\
$\mathrm{Total}$ & 99,75 & 99,82 & 99,76 & 99,81 & 99,51 \\
& & & & & \\
$\mathrm{Cu}$ & 148 & 116 & 252 & 66,6 & 61,8 \\
$\mathrm{Ni}$ & 65,4 & 100 & 177 & 75,5 & 127 \\
$\mathrm{Co}$ & 42,1 & 49,6 & 41,6 & 46,7 & 40,4 \\
$\mathrm{Cr}$ & 123 & 190 & 357 & 174 & 263 \\
$\mathrm{~V}$ & 339 & 280 & 201 & 294 & 183 \\
$\mathrm{Zr}$ & 144 & 59,2 & 53,7 & 97,5 & 186 \\
$\mathrm{Y}$ & 37,4 & 23 & 25,2 & 29 & 26,9 \\
$\mathrm{Nb}$ & 6,29 & 2,67 & 2,14 & 3,76 & 7,63 \\
$\mathrm{Ga}$ & 22 & 18,4 & 14,7 & 18,5 & 17,2 \\
$\mathrm{Ba}$ & 323 & 109 & 126 & 118 & 2240 \\
$\mathrm{Rb}$ & 65,92 & 58,64 & 17,83 & 7,88 & 59,02 \\
$\mathrm{Sr}$ & 95,3 & 91,7 & 137 & 112 & 61,3 \\
& & & & & \\
$\mathrm{La}$ & 13,13 & 5,96 & 13,81 & 5,8 & 32,78 \\
$\mathrm{Ce}$ & 28,62 & 13,83 & 9,74 & 14,54 & 67,49 \\
$\mathrm{Pr}$ & 3,71 & 1,87 & 2,21 & 1,96 & 6,83 \\
$\mathrm{Nd}$ & 17,77 & 8,69 & 9,51 & 9,5 & 26,68 \\
$\mathrm{Sm}$ & 5,08 & 2,52 & 2,76 & 3,09 & 5,1 \\
$\mathrm{Eu}$ & 1,65 & 1,03 & 0,96 & 1,08 & 1,75 \\
$\mathrm{Gd}$ & 5,59 & 3,31 & 3,66 & 4,12 & 4,88 \\
$\mathrm{~Tb}$ & 0,9 & 0,53 & 0,63 & 0,66 & 0,74 \\
$\mathrm{Dy}$ & 6,02 & 3,42 & 4,12 & 4,46 & 4,66 \\
$\mathrm{Ho}$ & 1,44 & 0,89 & 1,01 & 1,13 & 1,07 \\
$\mathrm{Er}$ & 3,66 & 2,33 & 2,54 & 2,86 & 2,68 \\
$\mathrm{Tm}$ & 0,54 & 0,35 & 0,39 & 0,47 & 0,41 \\
$\mathrm{Yb}$ & 3,64 & 2,27 & 2,43 & 2,87 & 2,78 \\
$\mathrm{Lu}$ & 0,52 & 0,33 & 0,38 & 0,43 & 0,41 \\
\hline & & & & & \\
\hline
\end{tabular}

Neste estágio a pressão magmática foi maior que a pressão tectônica ligada aos esforços coaxiais de direção N-S.

As estruturas mencionadas acima foram afetadas por dobras de plano axial subvertical e de direção E-W, geralmente abertas nas partes centrais dos plútons e fechadas na periferia, o que atesta um aumento gradual da intensidade da deformação nas bordas dos plútons. A formação destas estruturas é atribuída ao somatória de esforços de inchamento com esforços regionais coaxiais de direção N-S. A natureza coaxial dos esforços é confirmada pela presença de cisaThamentos conjugados observados na escala microscópica, assim como pelo achatamento do quartzo. Nesta fase, a pressão magmática foi menor que a pressão tectônica propiciando um maior achatamento dos plútons. Injeções tardias com bandamento magmático subvertical foram colocadas nesta fase.

As zonas miloníticas antes interpretadas como ligadas ao desenvolvimento de sistemas transcorrentes (Araújo et al. 1988, Costa et al. 1990, Barros \& Dall'Agnol 1994) são hoje atribuídas à formação de zonas de instabilidade mecânica em um estágio avançado de consolidação do magma. Este comportamento estrutural é típico de corpos graníticos sintectônicos (Capais 1989, Brun et al. 1990).

A extensão do magmatismo granítico alcalino tardi-arqueano na Região de Carajás As difíceis condições de acesso e de afloramento nos domínios do Granito Old Salobo têm dificultado a sua delimitação. Porém, ao que tudo indica, as rochas datadas por Machado et al. (1991) e por Souza (1996) pertencem ao mesmo corpo, cuja área de ocorrência parece ser maior do que a atualmente admitida. Domínios situados a norte da Serra Norte, considerados por muitos como janelas de embasamento parecem corresponder a extensões, para leste, do Granito Old Salobo ou de corpos cronocorrelatos. Isto pode ser confirmado pela semelhança da evolução metamórfica das rochas 
metavulcano-sedimentares situadas no alvo Salobo (Lindenmayer 1990, Winter 1994) e nas proximidades dos alvos N4 e N1, com a evolução das rochas encaixantes do Complexo Granítico Estrela. Ou seja, em N4 e N 1 observa-se igualmente um aumento do grau metamórfico à medida em que se aproxima de rochas "cristalinas" (Olszewsky et al. 1989, Matta \& Teixeira 1990) antes atribuídas ao embasamento (Complexo Xingu).

CONCLUSÕES O Complexo Granítico Estrela aflora a leste da Serra dos Carajás sob a forma de um corpo alongado na direção E-W. Critérios petrográficos, geoquímicos, estruturais e geofísicos permitem concluir que este maciço é formado por vários plútons e em muitos casos pela mistura algo heterogênea de tipos petrográficos diferentes, preferindo-se a denominação "Complexo Granítico Estrela" em substituição à nomenclatura anterior "Gnaisse Estrela". Esta denominação é mais coerente, uma vez que as rochas do mesmo não são verdadeiros gnaisses metamórficos e as suas feições estruturais são inteiramente ligadas à história de sua colocação.

A evolução estrutural do Complexo Estrela é marcada pelo desenvolvimento de um bandamento magmático de disposição concêntrica (subhorizontal nas porções centrais e subverticais nas periferias dos plútons) que reflete efeitos de fluxo num regime de inchamento (ballooning). Uma foliação de plano axial com direção E-W, a qual pode ter um bandamento magmático secundário associado, traduziria esforços coaxiais de direção N-S somados a esforços ligados à colocação do complexo granítico. Zonas miloníticas decimétricas a métricas são interpretadas como o resultado da formação de zonas de instabilidade mecânica, no finnal da consolidação do maciço. Esta história de deformação progressiva durante um regime termal decrescente comprova o caráter sintectônico do Complexo.

Geoquimicamente comparável aos granitos do tipo A, o Complexo Granítico Estrela tem provavelmente uma origem ligada à fusão parcial de rochas crustais, em condições relativamente anidras sob temperaturas elevadas $\left(\sim 900^{\circ} \mathrm{C}\right)$. Magmas desta natureza podem atingir níveis rasos da crosta por apresentarem baixa viscosidade.

A associação litológica (metabasaltos, metaultramáficas, formações ferríferas, quartzitos, metapelitos e rochas calcissilicáticas) somada à composição química dos metabasaltos (toleíticos ricos em ferro) permitem interpretar as seqüências supracrustais encaixantes do Complexo como do tipo greenstone-belt.

A evolução tectono-metamórfica destas supracrustais é marcada por uma fase de metamorfismo $\left(\mathrm{M}_{0}\right)$ essencialmente estático, de caráter hidrotermal e de fácies xisto verde. Na segunda fase $\left(\mathrm{M}_{1}\right)$ se formou uma foliação discreta em condições de fácies xisto verde (zona da biotita). A terceira fase $\left(\mathrm{M}_{2}\right)$ corresponderia aos efeitos de contato provocados pelo Complexo Granítico Estrela sobre as rochas metavulcano-sedimentares, onde três domínios foram distinguidos: uma auréola externa $\left(450-550^{\circ} \mathrm{C}\right)$, uma auréola interna $\left(550-650^{\circ} \mathrm{C}\right)$ e a zona de xenólitos $\left(650-850^{\circ} \mathrm{C}\right)$. A presença freqüente de veios de anfíbólio cortando rochas metabásicas indicam fraturamento hidráulico como uma resposta às reações de desidratação das assembléias preexistentes de baixo grau. Estas reações seriam induzidas pelo aumento do gradiente térmico provocado por estas intrusões graníticas alcalinas de idade tardi-arqueana.

A reabertura do sistema isotópico $\mathrm{Rb}-\mathrm{Sr}$ no final do arqueano $(2,5$ Ga) na região de Carajás deve estar, provavelmente, ligada à colocação dos corpos graníticos tardi-arqueanos de tendência alcalina (Complexo Granítico Estrela e Granito Old Salobo).

O empilhamento estratigráfico e a evolução tectono-metamórfica observados por outros autores nos domínios dos alvos Salobo e Pojuca são semelhantes aos das seqüências metavulcano-sedimentares encaixantes do Complexo Granítico Estrela. Isto reforça a importância da granitogênese tardi-arqueana na história tectono-metamórfica na região de Carajás, colocando, por conseguinte, fortes restrições aos modelos estruturais preexistentes que consideram a evolução da região de Carajás como ligada a um cinturão de cisalhamento transcorrente com movimentação oblíqua. A fase de metamorfismo de alta temperatura e baixa pressão, de amplitude quase regional que afeta as seqüências metavulcano-sedimentares, não tem ligação com ambiente de rift continental, ao contrário, tem íntima relação espaço-temporal com a colocação de granitos tardi-arqueanos sintectônicos a esforços compressivos.

Agradecimentos Ao Conselho Nacional de Desenvolvimento Científico e Tecnológico (CNPq) pela bolsa de estudo ao primeiro autor, ao PADCT-FINEP (4/3/87/0911/00 e 6.5.92.0025.00) pelos recursos financeiros, ao Centro de Geociências da Universidade Federal do Pará pela infra-estrutura e empréstimo de grande quantidade de amostras e de lâminas delgadas, à Universidade Henri Poincaré (Nancy I), ao Centre de Recherches Pétrografiques et Géochimiques (CRPG-CNRS), e ao Grupo Petrologia de Granitóides (CG-UFPa) na pessoa do Prof. Roberto Dall'Agnol pelas respectivas infra-estruturas e despesas de campo, à Anne-Marie Boullier e José Pons pelas sugestões e aos dois relatores anônimos da RBG pelas críticas e sugestões ao manuscrito. Muitas das conclusões deste trabalho fundamentam-se em dados de análises de química mineral (Service de Microanalyse-Université Henri Poincaré), obtidos com a colaboração do Sr. Jean Marie Claude, a quem prestamos nossa homenagem.

\section{Referências}

Almeida, F.F.M.; Hasui, Y.; Brito Neves, B.B. \& Fuck, R.A. 1981. Brasilian structural provinces: an introduction. Earth-Science Reviews, 17:1-29.

Althoff, F.J. 1996. Elude pétrologique et structurale de granitoides de Marajoara (Pará, Brésil): leur role dans l'évolution archéenne du craton amazonian (2.7-3.2 Ga). Nancy, $296 \mathrm{p}$ (Tese de Doutorado, Univcrsité Henri Poinearé-Nancy 1).

Althoff, F.J.; Barbey, P.; Boullier, A.M. \& Dall'Agnol, R. 1995. Composição e estrutura de granitoides arqueanos da região de Marajoara. Boletim Paraense Emílio Goeldi, 7:5-26.

Amaral, G. 1984. Provincia Tapajós e Província Rio Branco. In: Almeida, F.F \& Hasui, H. cds. O Pré-Cambriano do Brasil. São Paulo, Edgar Blücher. p. 6-35.

Anderson, J.L. \& Bender, E. 1989. Nature and origin of Proterozoic A-type granitic magmatism in the southwestern United States of America. Lithos, 23:19-52.

Andrade, J.B.F. 1991. In: Araújo O.J.B. \& Maia R.G.N. cds. Programa Levantamentos Geológicos Básicos do Brasil. Programa Grande Carajás. Serra dos Carajás. Folha SB.22-Z-A. Estado do Pará. Texto Explicativo. Brasília, DNPM/CPRM, p. 69-77.

Araújo, O.J.B.; Maia, R.G.N.; Jorgc-João, X.S.; Costa, J.B.S. 1988. A Megaestruturação Arqueana da Folha Serra dos Carajás. In: Congresso Latino-americano de Geologia, 7 , Belém, 1988. Anais..., Belém, SBG. v.1, p. 324-338.

Araújo, O.J.B. Macambira, E.M.B.; Vale, A.G.; Oliveira, J.R · Silva Neto, C.S.; Costa, E.J.S. Santos, A.; Pena Filho, J.I.C.; Neves, A.P.; Jorge-João, X.S. \& Costa, J.B.S. 1994. Primeira integração das investigações geológicas do Programa Grande Carajás na região SE do Estado do Pará. In: Simpósio de Geologia da Amazônia, 4, Belém, 1994, Resumos Expandidos..., Belém, SBG. p. 299-301.

Arndt, N.T.; Naldrct, A.J.; Pykc, D.R. 1977. Komatiitic and iron-rich tholeiitic lavas of Munro Township, northeast Ontario, Journal of Petrology, 18:319-369.

Avelar, V.G. 1996. Geocronologia Pb-Pb por evaporação em monocristal de zircão do magmatismo da região de Tucumã, SE do Estado do Pará, Amazônia oriental. Belém, 149 p. (Dissertação de Mestrado, Universidade Federal do Pará).

Balk, R. 1937. Structural beliaviour of igneous rocks. Geológica! Socicty of America. 177 p.

Barbosa, A.B.; Lafon, J.M.; Neves, A.P.; Vale, A.G. 1995. Geocronologia Rb-Sr c Pb-Pb do Granito Redenção, SE do Pará: Implicações para a evolução do magmatismo protcro/.óico da Região de Redenção. Boletim do Museu Paraense Emilio Goeldi, Ciências da Terra, 7:147-164.

Barros, C.E.M. 1991. Evolução petrológica e estrutural do Gnaisse Estrela, Curionópolis, PA. Belém, 134 p. (Dissertação de Mestrado, Universidade Federal do Pará).

Barros, C.E.M. 1997. Pétrologie et structure du Complexe Granitique Estrela $(2.5 \mathrm{Ga})$ et de son encaissant métavolcano-sédimentaire (Province Métallifère de Carajás, Brésil). Nancy, 316p. (Tese de Doutorado, Univcrsilé Henri Poincaré-Nancy 1).
Barros, C.E.M. \& Dall'Agnol, R. 1994. Deformação de rochas granitoides em regime dúctil: o exemplo do Gnaisse Estrela, Região de Carajás. Revista Brasileira de Geociências, 24(3): 129-138

Barros, C.E.M.; Dall'Agnol, R.; Barbey, P.; Boullier, A.M. 1997. Gcochemistry of the Estrel Granite Complex, Carajás Region, Brazil: an example of an Archaean A-typc granitoid. Journal of South-American Earth Sciences, 10(3-4):321-330.

Barros, C.E.M.; Dall'Agnol, R.; Lafon, J.M.; Teixeira, N.P.; Ribeiro, J.W. 1992. Geologia c gcocronologia Rb-Sr do Gnaisse Estrela, Curionópolis, PA. Boletim do Museu Paraense Emilio Goeldi, Ciências da Terra, 4:83-104.

Barros, C.E.M · Dall'Agnol, R · Soares, A.D.V.; Dias, G.S. 1994 Mctagabros de Águas Claras, Serra dos Carajás: pctrografia, geoquímica e transformações metamórfico-hidrotermais. Acta Geológica Leopoldensia, 40:31-70.

Bateman, R. 1984. On the role of diapirism in the segregation, ascent and final emplacement of granitoids. Tectonophysics, 10:211-231.

Bateman, R. 1985. Aurcole deformation by flattening around a diapir during in-situ ballooning: the Cannibal Creek granite. Journal of Geology, 93:293-310.

Beisigel, W.R.; Bernardelli, A.L.; Drumond, N.F.; Ruff, A.W.; Tremaine, J.W. 1973. Geologia e recursos minerais da Serra dos Carajás. Revista Brasileira de Geociências, 3(3):215-242.

Blais, S. 1989. Les ceintures de raches vertes archéenes de Finlande orientale. Géologie, Pétrologie, Géochimie et Evolution Géodynamique. Rennes, 256 p. (Tese de Doutorado, Université de Rennes I).

Brun, J.P. \& Pons, J. 1981. Slrain patlerns emplacement in a crust undergoing non-coaxia deformalion, Sierra Morena, Southern Spain. Journal of Structural Geology, 3(3):219-229

Brun, J.P.; Gapais, D.; Cognc, J.P.; Ledru, P.; Vigneresse, J.L. 1990. The Flamanville granite (Northwest Franco): an unequivocal example of syntectonically expanding plúton. Geológical Journal, 25:271 -286.

Castro, A. 1987. On granitoid emplacement and related structures. A review. Geologische Rundschau, 6(1): 101-124.

Cattel, A.C. \& Taylor, R.N. 1990. Archaean basic magmas. In R.P. Hall \& D.J. Hughes eds. Early Precambrian Basic Magmatism. Glasgow, Blackic \& Son Limited. $486 \mathrm{p}$

Clemens, J.D.; Holloway, J.R.; White, A.J.R. 1986. Origin of an A-type granitc: experimental constraints. American Mineralogist, 71:317-324.

Clemens, J.D. \& Mawcr, C.K. 1992. Granitic magma transport by fracture propagation. Tectonophysics, 204, 339-360.

Condic, K.C. 1994. Greenstones through the time. In Condie K.C ed. Archean crustal evolution. Amsterdam, Elsevier. p. 85-120.

Cordeiro, A.C. 1982. Geologia preliminar da região de Andorinhas. In: Simpósio de Geologia da Amazônia, 1, Belém, 1982. Anais..., Belém, SBG. v. 1, p. 45-49. 
Costa, J.B.S.; Teixeira, N.P.; Pinheiro, R.V.L.; Bermerguy, R.L. 1990. Os sistemas estruturais transcorrentes do Cinturão Itacaiúnas na Região de Curionópolis, Leste do Estado do Pará In: Congresso Brasileiro de Geologia, 35, Natal, 1990. Anais..., Natal, SBG. v. 5, p. 2345-2352.

Creaser, R.A.; Price, R.C.; Wormald, R.J. 1991. A-type granites revisited: Assessment of a residual-source model. Geology, 19:163-166.

Cullers, R.L.; Koch, R.; Bickford, M.E. 1981. Chemical evolution of magmas in the igneous terrane of St. François Mountains, Part II. Trace element evidence. Journal ofPetrology, 14:349-380.

Dall'Agnol, R.; Lafon, J.M.; Macambira, M.J.B. 1994. Proterozoic anorogenic magmatism in the Central Amazonian Province, Amazonian Craton: geochronological, petrological and geochemical aspects. Mineralogy and Petrology, 50(1/3):113-138.

Dias, G.S.; Macambira, M.J.B.; Dall'AgnoI, R.; Soares, A.D.V.; Barros, C.E.M. 1996. Datação de zircões de sill de metagabros: comprovação da idade arqucana da Formação Águas Claras, Carajás-Pará. In: Simpósio de Geologia da Amazônia, 5, Belém, 1996. Resumos expandidos..., Belém, SBG. p. 376-379.

Docegeo (Rio Doce Geologia e Mineração) 1988. Revisão litoestraligráfica da província mineral de Carajás. In: Congresso Brasileiro de Geologia, 35, Belém, 1988. Província Mineral de Carajás-Litoestratigrafia e principais depósitos minerais. Anexo aos anais... Belém, CVRD/SBG. 11-59.

Duarte, K. D. \& Dall'Agnol, R. 1992. Petrologia do Granito Mata-Surrão: um exemplo de monzogranito arqueano da região de Rio Maria (SE do Estado do Pará). In: Congresso Brasileiro de Geologia, 37, São Paulo, 1992. Resumos expandidos..., São Paulo, SBG. p. 341-342.

Evensen, N.M.; Hamilton, P.J.; O'Nions, R.K. 1978. Rare-earth abundances in chondrilic meteorites. Geochimica et Cosmochimica Acta, 42:1199-1212.

Gapais, D. 1989. Les orthogneiss-structures, mécanismes de déformation et analyse cinématique. Mémoires et Documents du Centre Armoricain d'Etude Structurale des Socles, Rennes, n 28,366 p.

Gapais, D.; Bale, P.; Chouckroune.P.; Cobbold, P.R.; Mahjoub, Y.; Marquer, D. 1987. Bulk kinematics from shear zone patterns: some field examples. Journal of Structural Geology, 9(5/6):635-646.

Gibbs, A.K.; Wirth, K.R.; Hirata, W.K.; Olszewski Jr., W.J. 1986. Age and composition of the Grão-Pará Group Volcanics, Serra dos Carajás. Revista Brasileira de Geociências, 16(2):201-211

Gomes, C.B.; Cordani, U.G.; Basei, M.A.S. 1975. Radiometric ages from the Serrados Carajás Area, Northern Brazil. Geological Society of America Bulletin, 86:932-942.

Gonçalez, M. G. B.; Dall'AgnoI, R.; Vieira, E.A.P.; Macambira, M.J.B.; Delia Senta, N. 1988. Geologia do Maciço Anorogônico Cigano, vale do rio Parauapebas, PA. In: Congress Brasileiro de Geologia, 35, Belém, 1988. Anais.... Belém, SBG. v. 3, p. 1132-1146.

Hirata, W.K.; Rigon, J.C.; Kadekaru, K.; Cordeiro, A.A.C., Meireles, E.M. 1982. Geologia Regional da Província Mineral de Carajás. In: Simpósio de Geologia da Amazônia, 1, Belém, 1982. Anais..., Belém, SBG. v. 1, p. 100-110.

Hutchinson, R.W. 1979. MMl-Salobo e suas relações geológicas regionais. Relatório sobre o Projeto Cobre-Docegeo. Docegeo, Distrito Amazônia, relatório inédito, Belém, 21 p.

Irvine, T.N. \& Baragar, W.R.A., 1971. A guide to the chemical elassification of the common volcanic rocks. Canadian Journal of Earth Sciences, 8:523-546.

Jorge-João, X.S.; Lobato, T.A.M.; Marques, M.T.G. 1991. Litogeoquímica-petroquímica. In: Araújo O.J.B. \& Maia G.G.N eds. Programa Levantamentos Geológicos Básicos do Brasil. Programa Grande Carajás. Serra dos Carajás. Folha SB.22-Z-A. Estado do Pará. Brasil. Programa Grande Carajas. Serra dos Carajas.
Texto Explicativo, DNPM/CPRM, Brasília, p. 79-95.

Lafon, J.M.; Rodrigues, E.; Duarte, K.D. 1994. Le granite Mata Surrão: Un magmatism $\begin{array}{llr}\text { monzogranitique des } & \text { contemporain assoeiations } \\ \text { tonalitiques-trondhjemitiques-granodioriliques archéenes de Ia région de Rio Maria }\end{array}$ (Amazonic orientale, Brésil). Comptes Rendues de l'Academie de Science de Paris, 1.318:643-649.

Laird, J. \& Albce, A.L. 1981. Pressure, temperature, and time indicators in mafic schisl: their application to reconstructing the polymetamorphic history of Vermonl. American Journal of Science, 281:127-175.

Landerberger, B. \& Collins, W.J. 1996. Derivation of A-type Graniles from a Dehydrated Charnockitic Lower Crust: Evidence from a Chaclundi Complex, Eastern Austrália. Journal of Petrology, 37(1): 145-170.

Leake, B.E. et al. 1997. Nomenclalure of amphiboles. Report of the Subcommitee on Amphiboles of the International Mineralogical Association Commission on New Minerais and Mineral Names. European Journal of Mineralogy, 9:623-651

Leite, A.S. 1995. Geologia e geoquímica do maciço granítico arqueano Xinguara e de suas encaixantes, Sudeste do Estado do Pará. Belém, 209 p. (Dissertação de Mestrado, Universidade Federal do Pará).

Leite, A.S. \& Dall'Agnol, R. 1994. Estratigrafia e aspectos geológicos da região de ocorrência do Granito Xinguara (SE do Pará). In: Simpósio de Geologia da Amazônia, 4, Belém, 1994. Resumos exandidos, Belém, SBG. p. 325-327.

Lindenmayer, Z.G. 1990. Salobo Sequence, Carajás, Brazil: geology, geochemistry and metamorphism. Ontario, 406p. (Tese de Doutorado, The University of Western Ontario).

Lindenmayer, Z.G. \& Fyfe, W.S. 1991. Metamorfismo de alta temperatura e baixa pressão no depósito de cobre do Salobo: evidência de rift continental arqueano no Craton Amazônico. In: Simpósio de Geologia da Amazônia, 3, Belém, 1991. Anais..., Belém, SBG. p.36-48.

Lindenmayer, Z.G. \& Fyfe, W.S. 1992. Comparação preliminar entre os metabasallos dos grupos Parauapebas e Salobo da Bacia Carajás, Estado do Pará. In: Congresso Brasileiro de Geologia, 37, São Paulo, 1992. Resumos expandidos...., São Paulo, SBG. v. 2, p. 33-34.

Lindenmayer, Z.G.; Fyfe, W.S.; Bocalon, V.L.S. 1994a. Nota Preliminar sobre as Intrusões Granitóides do Deposito de Cobre do Salobo, Carajás. Acta Geológica Leopoldensia, 40(XVII): 153-184.

Lindenmayer, Z.G.; Fyfe, W.S.; Laux, J.H. 1994b. Contribuição à Petrologia dos Metabasaltos do Grupo Salobo, Carajás, Pará. Acta Geológica Leopoldensia, 40(XVII): 115-152.

Macambira, E.M.B.; Jorge-João, X.S.; Souza, E.C. 1996. Geologic and petrological aspects of the Plaquê Granite-Southcastern of Pará State. In: Symposium Archacan Terranes of the South American Platform, Brasília, 1996. Extended abstracts..., Brasília, SBG. p. 73-75.

Macambira, M.J.B. 1992. Chronologie U-Pb, Rb-Sr, K-Ar et croissance de Ia croüte continental dans l'Amazonie du sud-est, exemple de Ia région de Rio Maria, Province de Carajás, Brésil. Montpellier, 212p. (Tese de Doutorado, Université de Montpellier II).

Macambira, M. J. B. \& Lafon, J.M. 1995. Geocronologia da Província Mineral de Carajás; síntese dos dados e novos desafios. Boletim Paraense Emílio Goeldi, 7:263-288.

Macambira, M. J. B.; Lafon, J.M.; Barradas, J.A. 1991. Le granite de Xinguara, témoin d'un magmatisme monzogranitique dans 1'Archéen de l'Amazonic Orientale, Brésil. Comptes Rendus de l'Académie de Sciences de Paris, 313(2):781-785.
Macambira, M.J.B. \& Lancelot, J. 1991. Em busca do embasamento arqueano da região de Rio Maria, sudeste do Estado do Pará. In: Simpósio de Geologia da Amazônia, 3, Belém, 1991. Anais..., Belém, SBG. p. 49-58.

Macambira, M. J. B. \& Lancelot, J. 1992. Idade U-Pb em zircões de metavulcânica do greenston do Supergroupo Andorinhas, delimitante da estratigrafia de Carajás, Estado do Pará. In: Congresso Brasileiro de Geologia, 37, São Paulo, 1992. Resumos expandidos..., São Paulo, SBG. v. 2, p. 188-189.

Machado, N.; Lindenmayer, Z.; Krogh, T.H.; Lindenmayer, D. 1991. U-Pb geoehronology of Archaean magmatism and basement reactivation in the Carajás área, Amazon shield, Brazil. Precambrian Research, 49:329-354

Matta, M.A.S. \& Teixeira, N.P. 1990. Mapeamento e análise estrutural das unidades lilo-estruturais aflorantes na região do platô N-5, Serra Norte/Carajás. In: Congresso Brasileiro de Geologia, 36, Natal, 1990. Anais..., Natal, SBG. v. 5, p. 2309-2320.

Medeiros, H. \& Dall'Agnol, R. 1988. Petrologia da porção leste do batólito Granodiorítico Rio Maria, sudeste do Pará. In: Congresso Brasileiro de Geologia, 35, Belém, 1988. Anais... Belém, SBG. v. 3, p. 1488-1499.

Meireles, E.M.; Hirata, W.K.; Amaral, A.F.; Medeiros F_, C.A.; Gato, V.C. 1984. Geologia das folhas Carajás e Rio Verde, Província Mineral de Carajás, Estado do Pará. In: Congresso Brasileiro de Geologia, 33, 1984, Rio de Janeiro. Anais..., Rio de Janeiro, SBG. v. 5, p. 2164-2174.

Morimoto, N. 1988. Nomenclature of pyroxenes. Bulletin de Minéralogie, 11:535-550.

Mougeot, R.: Respaut, J.P.; Ledru, P.; Milesi, J.P.; Macambira, M.J.B. Huhn, S.B. 1996. Contrainte géochronologique U-Pb pour l'âge de Ia formation sédimentaire de Águas Claras (Province de Carajás, Etat de Pará.). In: Reunion des Sciences de la Terre, 16, Orléans, 1996. Resumes..., Orléans, BRGM. p. 67.

Nogueira, A. C. 1995. Análise faciológica e aspectos estruturais da Formação Águas Claras, Região Central da Serra dos Carajás-Pará. Belém, 167p. (Dissertação de Mestrado, Universidade Federal do Pará).

Nogueira, A.C.R.; Truckenbrodt, W.; Pinheiro, R.V.L. 1995. Formação Águas Claras, Pré-Cambriano da Serra dos Carajás: redescrição e redefinição litostratigráfica. Boletim do Museu Paraense Emílio Goeldi, Ciências da Terra, 7:177-277.

Oliveira, E. P.; Winter, C.; Sachs, L.; Batista, J.J.; Figueiredo, B.; Foster, R. 1993. Limiting factors in applying geochemistry to tectonic setting identification in continental área: implication to the Carajás basic melavolcanics, Brazil. In: Congresso Brasileiro de Geoquímica, 4, Brasília, 1993. Resumos..., Brasília, SBGq. p. 20-22.

Olszewski Jr.; Wirth, K.R.; Gibbs, A.K.; Gaudette, H.E. 1989. The age, origin and tectonic of the Grão-Pará Group and associated rocks, Serra dos Carajás, Brazil: Archean Continental volcanism and rifting. Precambrian Research, 42:229-254.

Paterson, S.R.; Vernon, R.H. ; Fowler, Jr., T.K. 1991. Aureole systematics. In Ribbe, P.H. ed. Contact Metamorphism. Reviews in Mineralogy, 26, p. 673-722.

Passehier, C.W. \& Trouw, R.A.J. 1996. Microtectonics. Berlin, Springer-Verlag. 289p.

Pimentel, M.M. \& Machado, N. 1994. Geocrologia U-Pb dos terrenos granito-greenstone de Rio Maria, Pará. In: Congresso Brasileiro de Geologia, 38, Camboriú, 1994. Resumos. Camboriú, SBG. v. 2, p. 390-391.

Pinheiro, R. V. L. 1997. Reactivation history of the Carajás and Cinzento Strike-Slip Systems, Amazon, Brazil. Durham, 408 p. (Tese de Doutorado, University of Durham)

Pinheiro, R. V. L. \& Holdsworth, R.E. 1997. Reaetivation of Archacan strike-slip fault systems, Amazon region, Brazil. Journal of the Geological Society of London, 154:99-103.

Pons, J.; Barbey, P.; Dupuis, D.; Leger.J.M. 1995. Mechanism of pluton emplacement and structural evolution of a 2.1 Gajuvenile continental crust: The Birmanian of southwestern Niger. Precambrian Research, 70:281-301.

Renne, P. R.; Onstott, T.; Jorge-João. $1988 .{ }^{40} \mathrm{Ar} /{ }^{39} \mathrm{Ar}$ and paleomagnetic results from the Guaporé Shield: further implications for the nature of middle-late proterozoic mobile belts of Gondwanaland. In: Congresso Latino-Americano de Geologia, 7, Belém, 1988. Anais..., Belém, SBG. v. 1, p. 348-362.

Rios, F.J. 1991. O Granito Central: fades petrográficas e alteração hidrotermal do setor norte. Belém, 124p. (Dissertação de Mestrado, Universidade Federal do Pará)

Rivalenti, G.; Girardi, V.A.V.; Mazzucchelli, M.; Correia, C.T.; Molesini, M.; Finatti, M.C. 1992 Mafic Magmatism in the Carajás Region: a pelrological reconnaissance. In: Congresso Brasileiro de Geologia, 37, São Paulo, 1992. Resumos expandidos.... São Paulo, SBG. v. 1, p. 481-487.

Rodrigues, E.S.; Lafon, J.M.; Scheller, T. 1992. Geoeronologia Pb-Pb da Província Mineral de Carajás: primeiros resultados. In: Congresso Brasileiro de Geologia, 37, São Paulo, 1992. Resumos expandidos..., São Paulo, SBG. v. 2, p.183-184.

Silva, G.C.; Lima, M.I.C.; Andrade, A.R.F.; Issler, R.S.; GuimarSes, G. 1974. Geologia das folhas SB-22 Araguaia eparte da SC-22 Tocantins. Belém, DNPM, v.4, 1-143.

Skjerlic, K.P. \& Johnston, A.D. 1993. Fluid-absent melting behavior of an F-rich tonalitic gneiss at mid-crustal pressures: implications for the generation of anorogenic granites. Journal of Petrology, 34(4):785-815.

Soares, A.V.; Santos, A.B.; Vieira, E.A.; Bella, V.M., Martins, L.P.B. 1994. Área Águas Claras: contexto geológico e mineralizações. In: Simpósio de Geologia da Amazônia, 4, Belém, 1994. Resumos expandidos... Belém, SBG. p. 379-382.

Souza, S.R.B. 1996. Estudo geocronológico e de geoquímica isotópica da área Pojuca (Província Mineral de Carajás-PA). Belém, 106p. (Dissertação de Mestrado, Universidade Federal do Pará).

Streckeisen, A.L. 1976. To cach plutonic rock its proper name. Earth-Science Reviews, 12:1-33. Sylvester, P.J. 1989. Post-collisional alkaline granites. Journal of Geology, 97:261-280. Sylvester, P.J. 1994. Archean granite plutons. In: Condie K. ed. Archean Crustal Evolution.-Developments in Precambrian Geology J I. Amsterdam, Elsevier. p. 297-323.

Teixeira, J.B.G. \& Eggler, D.H. 1994. Pelrology, geochemistry, and tectonic setting of Archean basaltic and diorilic rocks from the N4 iron deposit, Serra dos Carajás, Pará, Brazil. Acta Geológica Leopoldensia, 40(XVII):71-114

Turner, F.J. 1968. Metamorphic petrology (Mineral and field aspects). New York, Mc Graw-Hill.

403p.
Whalen, J.B.; Currie, K.L.; Chappell, B.W. 1987. A-type granites: geochemical characteristics, discrimination and petrogenesis. Contributions to Mineralogy and Petrology, 95:407-419.

Winter, C. 1994. Geology and base-metal mineralization associated with Archaean iron-formation in the Pojuca Corpo Quatro Deposit, Carajás, Brazil. (Tese de Doutorado, University of Southampton).

Wirth, K.R.; Gibbs, A.K.; Olszewski Jr., W.J. 1986. U-Pb ages of zircons from the Grão-Pará group and Serra dos Carajás granite, Pará, Bra/.il. Revista Brasileira de Geociências, 16(2): 195-200.

Manuscrito A-1006 